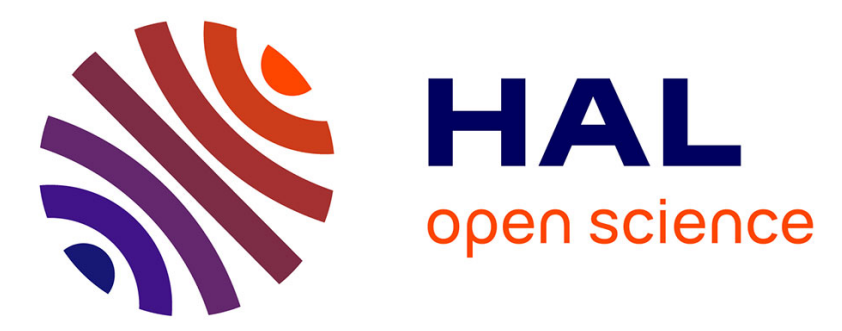

\title{
Effects of anions size on the redox behavior of poly(o-toluidine) in acid solutions. An in situ vis-NIR cyclic spectroelectrogravimetry study
}

J. Agrisuelas, Claude Gabrielli, J.J. Garcia-Jareño, Hubert Perrot, F. Vicente

\section{- To cite this version:}

J. Agrisuelas, Claude Gabrielli, J.J. Garcia-Jareño, Hubert Perrot, F. Vicente. Effects of anions size on the redox behavior of poly(o-toluidine) in acid solutions. An in situ vis-NIR cyclic spectroelectrogravimetry study. Electrochimica Acta, 2014, 125, pp.83-93. 10.1016/j.electacta.2014.01.036 . hal-01005760

\section{HAL Id: hal-01005760 \\ https://hal.sorbonne-universite.fr/hal-01005760}

Submitted on 20 Oct 2014

HAL is a multi-disciplinary open access archive for the deposit and dissemination of scientific research documents, whether they are published or not. The documents may come from teaching and research institutions in France or abroad, or from public or private research centers.
L'archive ouverte pluridisciplinaire HAL, est destinée au dépôt et à la diffusion de documents scientifiques de niveau recherche, publiés ou non, émanant des établissements d'enseignement et de recherche français ou étrangers, des laboratoires publics ou privés. 
Effects of anions size on the redox behavior of poly(o-toluidine) in acid solutions. An in situ vis-NIR cyclic spectroelectrogravimetry study.

\footnotetext{
J. Agrisuelas ${ }^{*, \dagger, \S}$, C. Gabrielli ${ }^{\dagger, \ddagger}$, J. J. García-Jareño $0^{\S}$, H. Perrot ${ }^{\dagger, \ddagger}$ and F. Vicente ${ }^{\S}$

† Laboratoire Interfaces et Systèmes Electrochimiques (LISE), UPR 15 du CNRS, Centre National de la Recherche Scientifique (CNRS), 4 place Jussieu, 75005 Paris, France

LISE, Université Pierre et Marie Curie-Paris 6 (UPMC), 4 place Jussieu, 75005 Paris, France

$\S$ Departament de Química Física, Universitat de València. C/Dr. Moliner, 50, 46100, Burjassot, València, Spain
}

*E-mail: jeronimo.agrisuelas@uv.es 


\begin{abstract}
The combination of different in situ techniques allows a more complete analysis combining several physical and chemical processes of polymer-modified electrodes to be obtained. The hybrid technique -cyclic electrogravimetry coupled with visible-near infrared spectroscopy- was used to study in depth the electrochemistry of poly(otoluidine) (POT) thin films. In this work, a POT modified electrode was polarized between the pernigraniline and leucoemeraldine forms in $0.5 \mathrm{M} \mathrm{HNO}_{3}$ and $0.5 \mathrm{M} \mathrm{HClO}_{4}$ solutions. The electrochromic properties of POT-ClO ${ }_{4}^{-}$and $\mathrm{POT}-\mathrm{NO}_{3}^{-}$were localized in the experimental potential range associated to the transfer of charged species during the redox reactions. The analysis of all the experimental results has allowed the main contribution of proton, anion and water transfers to be separated in three redox transitions together with the electrochromic properties of POT. Semi-quantitatively, the better electrochemical and electrochromic properties of both films take place predominantly at potentials where the higher accumulation of the radical cations (polarons and bipolarons) in the polymer structure involves great lattice reorganization. The analysis of this work is a complete objective manner to discriminate the better conditions where a film can be used for a specific technical application.
\end{abstract}

Keywords: Intrinsically conducting polymer, Reflectance, Spectroelectrochemistry, Electrochemical quartz crystal microbalance. 


\section{INTRODUCTION}

Over the past several decades, spectroelectrochemistry has revealed as a powerful tool for the elucidation of electron transfer processes [1,2]. One direction in this field of study is to modify the kind of interaction between matter and radiated energy. Interesting information about different physical properties can be obtained by analyzing altogether the information provided by the coupling of different in situ techniques. The high reflectance gold electrodes of electrochemical quartz crystal microbalances (EQCM) allow the spectroscopic radiation to be recorded together with the mass changes of a modified electrode during a cyclic voltammogram. In this manner, the cyclic spectroelectrogravimetry could be a good candidate to obtain a complete analysis during the continuous polarization of polymer-modified electrodes. It avoids any question of polymer history effects when sequential experiments and subsequent correlation of the data neglect temporal structural changes, such as relaxation within polymers $[3,4]$. Afterward, a subsequent intensive mathematical analysis is necessary to extract the interesting information from the large amount of experimental data. The coupling of different in situ techniques has been shown to be a powerful approach for studying electrochemically active materials as it allows different physical and chemical properties to be correlated [5-7].

Intrinsically conducting polymers (ICPs) have been the subject of many research efforts because of their environmental stability, good processability and their low relative cost [8-14]. The electrical conduction through the film needs to pass some potential barriers: 1) the electron transfer at the electrode|film interface, b) the electron transport through the film which will be neglected in this layer by supposing that deposited polymers are thin enough and finally c) the exchange of charged species (cations and anions) at the film|solution interface necessary for the electrical charge balance. During these processes, free solvent transfer between the solution and the polymer often occurs.

The understanding of the electrochemical behavior of these permselective polymers is essential and provides an important motivation for the present study since the potentiometric response, electrical conductivity, insertion kinetics of ions and/or free water molecules depends significantly on the size of incorporated ions $[15,16]$. Spectroscopy will allow an unequivocally identification of the electroactive species causing these transfers during the complex electrochemical redox reactions of conducting polymers [5]. Elucidation of these mechanisms will help to improve their properties of 
interest in several technologies like electrochromic devices [17,18], photogalvanic cells [19], artificial muscles [20,21], light-emitting electrochemical cells [22,23], biosensors [24-28], biofuel cells-based devices [29,30].

Among ICPs, poly(o-toluidine) (POT) is one of the most studied polymers [3139]. Previously in a diprotic acid [5], three different redox reaction steps were isolated between the non-conductive forms of POT: the oxidized form (pernigraniline salt, PN) and the reduced form (leucoemeraldine salt, LE). The intermediated conductive forms of POT (polarons, P, and bipolarons, BP) were considered as single entities with specific and independently measurable electrochemical properties. The reaction scheme proposed was:

$$
\begin{gathered}
\mathrm{LE}+n_{1} \mathrm{HSO}_{4}^{-} \underset{k_{1}}{\stackrel{k_{1}^{\prime}}{\rightleftarrows}} \mathrm{P}+n_{1} \mathrm{e}^{-}+x_{1} \mathrm{H}_{2} \mathrm{O} \\
\mathrm{P}+n_{2} \mathrm{HSO}_{4}^{-} \stackrel{k_{2}^{\prime}}{\rightleftarrows} \mathrm{kP}+n_{2} \mathrm{e}^{-}+x_{2} \mathrm{H}_{2} \mathrm{O} \\
\mathrm{BP}_{k_{3}^{\prime}}^{\stackrel{k_{3}}{\rightleftarrows}} \mathrm{PN}+n_{3} \mathrm{e}^{-}+n_{3} \mathrm{H}_{3} \mathrm{O}^{+}
\end{gathered}
$$

where $n_{i}$ represents the number of electrons or available sites inside the polymer for the insertion/expulsion of ionic species and $x_{i}$ is the number of water molecules exchanged during the electrochemical reaction. The redox reactions involving the anions $\left(\mathrm{HSO}_{4}^{-}\right)$ and water molecules are faster than the redox reaction involving hydrated protons, in

other words, $k_{1}^{\prime}>k_{3}$ and $k_{2}^{\prime}>k_{3}$ in the oxidation direction and $k_{1}>k_{3}^{\prime}$ and $k_{2}>k_{3}^{\prime}$ in the reduction direction [40].

In this work, POT films were generated in $0.5 \mathrm{M} \mathrm{H}_{2} \mathrm{SO}_{4}$ aqueous solutions on a gold electrode. These modified electrodes were studied by in situ spectroelectrogravimetry in two different aqueous solutions of $0.5 \mathrm{M}$ monoprotic acids: $\mathrm{HClO}_{4}$ and $\mathrm{HNO}_{3}$. The influence of these anions on the electrochemical response of the film and on the transfers of the other species during the electrochemical transitions was compared.

\section{THEORETICAL APPROACH}

The simplest model used to interpret voltammetric curves of electroactive films is assume that the reduced and the oxidized forms of the film are adsorbed and the Nernst equation is satisfied [41]. Simultaneously, the redox process involves insertion/expulsion of charged species for electrical stability. As an example for anions, it comes: 


$$
\langle\mathrm{P}\rangle+\mathrm{A}^{-} \underset{k_{\mathrm{A}^{-}}}{\stackrel{k_{\mathrm{A}^{-}}^{\prime}}{\rightleftarrows}}\left\langle\mathrm{P}^{+}, \mathrm{A}^{-}\right\rangle+\mathrm{e}^{-}
$$

where $\mathrm{A}^{-}$is the anion, $\langle\mathrm{P}\rangle$ is the site in the host polymer and $\left\langle\mathrm{P}^{+}, \mathrm{A}^{-}\right\rangle$is occupied site in the polymer matrix doped with anions. A similar approach can be made for the exchange of cations and solvent [42,43].

At the polymer|solution interface, the flux of anions is $J_{\mathrm{A}^{-}}=-d_{f}\left(d C_{\mathrm{A}^{-}} / d t\right)$ where $d_{f}$ is the polymer film thickness and $C_{\mathrm{A}^{-}}$the concentration of anions. For very thin films, the insertion/expulsion of species at the polymer|solution interface is considered the ratelimiting step and the change of $C_{\mathrm{A}^{-}}$is:

$$
\frac{d C_{\mathrm{A}^{-}}}{d t}=-k_{\mathrm{A}^{-}}\left(C_{\mathrm{A}^{-}}-C_{\mathrm{A}^{-}}^{\min }\right)+k_{\mathrm{A}^{-}}^{\prime}\left(C_{\mathrm{A}^{-}}^{\max }-C_{\mathrm{A}^{-}}\right) C_{\mathrm{A}^{-}}^{\text {sol }}
$$

where $C_{\mathrm{A}^{-}}^{\max }$ and $C_{\mathrm{A}^{-}}^{\text {min }}$ are the maximum and minimum concentrations of the electrochromic sites where anions can be inserted and $C_{\mathrm{A}^{-}}^{\text {sol }}$ is the outer concentration of anions. This equation can be simplified as:

$$
\frac{d C_{\mathrm{A}^{-}}}{d t}=-k_{\mathrm{A}^{-}}\left(C_{\mathrm{A}^{-}}\right)+k_{\mathrm{A}^{-}}^{\prime}\left(C_{\mathrm{A}^{-}}^{\max }-C_{\mathrm{A}^{-}}\right) C_{\mathrm{A}^{-}}^{\text {sol }}
$$

when $C_{\mathrm{A}^{-}}^{\text {min }}=0$.

For a potential sweep where eq (4) occurs, the current $d q / d t$ considering $q$ in $\mathrm{C}$ $\mathrm{cm}^{-2}$ is equal to:

$$
\frac{d q}{d t}=-v d_{f} F \frac{d C_{\mathrm{A}^{-}}}{d E}
$$

where $E=E_{0}-v t, v$ is the scan rate, $F$ is the Faraday constant and

$$
\frac{d C_{\mathrm{A}^{-}}}{d E}=k_{\mathrm{A}^{-}}^{\prime} k_{\mathrm{A}^{-}} C_{\mathrm{A}^{-}}^{s o l} \frac{\left(b_{\mathrm{A}^{-}}^{\prime}-b_{\mathrm{A}^{-}}\right) C_{\mathrm{A}^{-}}^{\max }}{\left(k_{\mathrm{A}^{-}}^{\prime} C_{\mathrm{A}^{-}}^{s o l}+k_{\mathrm{A}^{-}}\right)^{2}}
$$

Here, the kinetic constants are supposed to be activated by the potential (the classical Tafel law), such as:

$$
\begin{gathered}
k_{\mathrm{A}^{-}}^{\prime} C_{\mathrm{A}^{-}}^{\text {sol }}=k_{\mathrm{A}^{-0} 0}^{\prime} C_{\mathrm{A}^{-}}^{s o l} \exp \left(b_{\mathrm{A}^{-}}^{\prime} E\right)=k_{\mathrm{A}^{-0} 00}^{\prime} \exp \left(b_{\mathrm{A}^{-}}^{\prime}\left(E-E_{p}\right)\right) \\
k_{\mathrm{A}^{-}}=k_{\mathrm{A}^{-0} 0} \exp \left(b_{\mathrm{A}^{-}} E\right)=k_{\mathrm{A}^{-0} 00} \exp \left(b_{\mathrm{A}^{-}}\left(E-E_{p}\right)\right)
\end{gathered}
$$

where

$$
b_{\mathrm{A}^{-}}-b_{\mathrm{A}^{-}}^{\prime}=\frac{n F}{R T}
$$

and $R$ is the gas constant, $T$ is the absolute temperature, $E_{p}$ is the peak potential where the maximum current is reached. $n F / R T$ is about $40 \mathrm{~V}^{-1}$ at $298 \mathrm{~K}$ for a single electron transfer $(n=1)[44,45]$. 
Finally, we can obtain

$$
\frac{d q}{d t}=v d_{f} \frac{F^{2}}{R T} \frac{C_{\mathrm{A}^{-}}^{\max } \exp \left(\left(b_{\mathrm{A}^{-}}-b_{\mathrm{A}^{-}}^{\prime}\right)\left(E-E_{p}\right)\right)}{\left[1+\exp \left(\left(b_{\mathrm{A}^{-}}-b_{\mathrm{A}^{-}}^{\prime}\right)\left(E-E_{p}\right)\right)\right]^{2}}
$$

which may be mathematically rewritten by considering $\left(e^{-x}+e^{+x}\right) / 2=\cosh (x)$ as:

$$
\begin{aligned}
& \frac{d q}{d t}=v d_{f} \frac{F\left(b_{\mathrm{A}^{-}}-b_{\mathrm{A}^{-}}^{\prime}\right) C_{\mathrm{A}^{-}}^{\max }}{\cosh ^{2}\left[\frac{\left(b_{\mathrm{A}^{-}}-b_{\mathrm{A}^{-}}^{\prime}\right)}{2}\left(E-E_{p}\right)\right]} \\
& \text { where } v d_{f} F\left(b_{\mathrm{A}^{-}}-b_{\mathrm{A}^{-}}^{\prime}\right) C_{\mathrm{A}^{-}}^{\max }=\left(\frac{d q}{d t}\right)_{\text {peak }}
\end{aligned}
$$

This equation can be easily convert in changes of mass considering the molar mass of anion, $M_{\mathrm{A}^{-}}$and the direction of anion transfer $\delta_{\mathrm{A}^{-}}$during the electrochemical reaction as.

$$
\begin{gathered}
\frac{d m}{d t}=v d_{f} \frac{\delta_{\mathrm{A}^{-}} M_{\mathrm{A}^{-}}\left(b_{\mathrm{A}^{-}}-b_{\mathrm{A}^{-}}^{\prime}\right) C_{\mathrm{A}^{-}}^{\max }}{\cosh ^{2}\left[\frac{\left(b_{\mathrm{A}^{-}}-b_{\mathrm{A}^{-}}^{\prime}\right)}{2}\left(E-E_{p}\right)\right]} \\
\text { where } v d_{f} \delta_{\mathrm{A}^{-}} M_{\mathrm{A}^{-}}\left(b_{\mathrm{A}^{-}}-b_{\mathrm{A}^{-}}^{\prime}\right) C_{\mathrm{A}^{-}}^{\max }=\left(\frac{d m}{d t}\right)_{\text {peak }}
\end{gathered}
$$

In this case $\delta_{\mathrm{A}^{-}}=+1$ since the anions are inserted during the oxidation. On the contrary, $\delta$ is negative for species inserted during the reduction (i.e. cations).

Likewise, the absorbance changes at each wavelength $\lambda, d A^{\lambda} / d t$ of an electrochromic film can be related to the charge when the Lambert-Beer's law is satisfied:

$$
\frac{d A^{\lambda}}{d t}=\frac{1}{F} \varepsilon_{\mathrm{A}^{-}}^{\lambda} l \frac{d q}{d t}
$$

where $\varepsilon_{\mathrm{A}^{-}}^{\lambda}$ is the absorbance coefficient of the electrochromic sites and $l$ the length of the light pass. So,

$$
\begin{gathered}
\frac{d A^{\lambda}}{d t}=v d_{f} \frac{\varepsilon_{\mathrm{A}^{-}}^{\lambda} l\left(b_{\mathrm{A}^{-}}-b_{\mathrm{A}^{-}}^{\prime}\right) C_{\mathrm{A}^{-}}^{\max }}{\cosh ^{2}\left[\frac{\left(b_{\mathrm{A}^{-}}-b_{\mathrm{A}^{-}}^{\prime}\right)}{2}\left(E-E_{p}\right)\right]} \\
\text { where } v d_{f} \varepsilon_{\mathrm{A}^{-}}^{\lambda} l\left(b_{\mathrm{A}^{-}}-b_{\mathrm{A}^{-}}^{\prime}\right) C_{\mathrm{A}^{-}}^{\max }=\left(\frac{d A^{\lambda}}{d t}\right)_{\text {peak }}
\end{gathered}
$$

By some algebra, three instantaneous crossed functions may be calculated. From eq (14) and eq (13), it is easy to obtain a good estimation of the molar mass of the anion participating [46]:

$$
F\left(\frac{d m / d t}{d q / d t}\right)=F\left(\frac{d m}{d q}\right)=\delta_{\mathrm{A}^{-}} M_{\mathrm{A}^{-}}
$$


From eq (16) and eq (13), the absorbance coefficient is obtained (also called electrochromic efficiency) [47]:

$$
F\left(\frac{d A^{\lambda} / d t}{d q / d t}\right)=F\left(\frac{d A^{\lambda}}{d q}\right)=l \varepsilon_{\mathrm{A}^{-}}^{\lambda}
$$

In this function, $l \varepsilon_{\mathrm{A}^{-}}^{\lambda}$ is positive when the absorbance increases during the oxidation reaction $(d q / d t>0)$ or diminishes during the reduction reaction $(d q / d t<0)$. On the contrary, $l \varepsilon_{\mathrm{A}^{-}}^{\lambda}$ is negative when the absorbance increases during the reduction reaction or diminishes during the oxidation reaction.

It is also possible to obtain a different electrochromic efficiency at a given wavelength related to the changes of film mass owing to the anion transfer between the polymer and the solution from eq (16) and eq (14) [5]:

$$
\frac{d A^{\lambda} / d t}{d m / d t}=\frac{d A^{\lambda}}{d m}=\frac{l \varepsilon_{\mathrm{A}^{-}}^{\lambda}}{\delta_{\mathrm{A}^{-}} M_{\mathrm{A}^{-}}}
$$

Here, positive mass electrochromic efficiency can be found when absorbance increases during the insertion of anions $(d m / d t>0)$ or when absorbance diminishes during the expulsion of anions $(d m / d t<0)$. Likewise, this electrochromic efficiency is negative if the absorbance increases during the expulsion of anions or if the absorbance diminishes during the insertion of anions. In this manner, we remove the contributions due to catalytic reactions if these reactions do not affect both the color and the mass.

\section{EXPERIMENTAL}

\subsection{Film preparation}

The electrochemical polymer deposition and characterization was controlled by cyclic voltammetry (CV) through an AUTOLAB potentiostat-galvanostat set up (PGSTAT302) and an Electrochemical Quartz Crystal Microbalance (RQCM, Maxtek, Inc.). The three-electrode cell involves the $\mathrm{Ag}|\mathrm{AgCl}| \mathrm{KCl}_{\text {(sat) }}$ reference electrode (RE-1C, Bas Inc., Japan), a platinum counter electrode and the gold working electrode with an area of $0.3 \mathrm{~cm}^{2}$. It was patterned on a $9 \mathrm{MHz}$ quartz crystal resonator (TEMEX, France). All solutions were prepared with deionized and double-distilled water. The POT polymerization solution was $0.5 \mathrm{M} \mathrm{H}_{2} \mathrm{SO}_{4}$ (Fisher scientific, for trace analysis) and 0.2 M o-toluidine (Fluka) used as received. POT was formed through 100 voltammetric cycles between $-0.1 \mathrm{~V}$ and $+0.9 \mathrm{~V}$ with a $100 \mathrm{mV} \mathrm{s}^{-1}$ scan rate. 


\subsection{Film characterization}

The resulting modified electrode was cycled between $-0.1 \mathrm{~V}$ and $0.9 \mathrm{~V}$ vs SCE in $0.5 \mathrm{M} \mathrm{HNO}_{3}$ (Normapur AnalR) or in $0.5 \mathrm{M} \mathrm{HClO}_{4}$ (Normapur RP) at $100 \mathrm{mV} \mathrm{s}^{-1}$ until a stable cyclic voltammogram was obtained (after 10 cycles) assuming the complete substitution of bisulfate anions inserted during the polymerization process by the corresponding anion in POT ( $\mathrm{pH} \approx 0.45$ in both solutions).

After that, in order to monitor the chemical changes of POT during a cyclic voltammogram, a vis-NIR absorbance spectrum between $380 \mathrm{~nm}$ and $1100 \mathrm{~nm}$ was simultaneously collected in a PC through the EPP2000 Portable Fiber Optic Spectrometer (StellarNet Inc.) each $9 \mathrm{mV}$ (about 11 spectra/second) using a $2 \times 2 \mathrm{~cm}$ high-transmittance glass cell from Hellma ${ }^{\circledR}$ (OG quality) as the electrochemical cell. The color response received was recorded as number of counts at each wavelength, $n_{\text {counts }}^{\lambda}$, which is directly converted into light intensity at a given wavelength, $I^{\lambda}$, reflected on the gold electrode of the EQCM. In this work, it is preferred to convert into an apparent time derivative of absorbance at a specific wavelength $\left(A^{\lambda}\right)$ which was shown to be better for comparing with mass and electrical charge by means of the Lambert-Beer's law:

$$
\begin{gathered}
A^{\lambda}=-\log \left(I^{\lambda} / I_{0}^{\lambda}\right)=-\log \left(I^{\lambda}\right)+\log \left(I_{0}^{\lambda}\right) \\
\frac{d A^{\lambda}}{d t}=\frac{d\left(-\log \left(I^{\lambda}\right)+\log \left(I_{0}^{\lambda}\right)\right)}{d t}=-\frac{d\left(\ln \left(I^{\lambda}\right)\right)}{\ln (10) \cdot d t}=\frac{1}{2.303 I^{\lambda}} \frac{d I^{\lambda}}{d t}
\end{gathered}
$$

Since, the intensity of transmitted light, $I^{\lambda}$, is proportional to the number of counts, $n_{\text {counts }}^{\lambda}$, received by the diode at this wavelength, it can be written:

$$
\frac{d A^{\lambda}}{d t}=\frac{1}{2.303 I^{\lambda}} \frac{d I^{\lambda}}{d t}=\frac{1}{2.303 n_{\text {counts }}^{\lambda}} \frac{d n_{\text {counts }}^{\lambda}}{d t}
$$

The analysis of the raw data was carried out using the software Mathcad 14 (Mathsoft) where all data collected in the time domain were treated by using the Savitzky-Golay filter.

\section{RESULTS AND DISCUSSION}

\subsection{Optical characterization}

In a redox system like POT films in $\mathrm{H}_{2} \mathrm{SO}_{4}$ solutions, the total current is the sum of the partial currents relative to the contribution of 3 overlapped electrochemical 
processes in the oxidation direction and the reduction direction of a voltammogram scan (eq. (1)-(3)):

$$
\begin{aligned}
& \left.\frac{d q_{T}}{d t}\right|_{o x}=\frac{d q_{\mathrm{LE} \rightarrow \mathrm{P}}}{d t}+\frac{d q_{\mathrm{P} \rightarrow \mathrm{BP}}}{d t}+\frac{d q_{\mathrm{BP} \rightarrow \mathrm{PN}}}{d t} \\
& \text { and } \\
& \left.\frac{d q_{T}}{d t}\right|_{\text {red }}=\frac{d q_{\mathrm{PN} \rightarrow \mathrm{BP}}}{d t}+\frac{d q_{\mathrm{BP} \rightarrow \mathrm{P}}}{d t}+\frac{d q_{\mathrm{P} \rightarrow \mathrm{LE}}}{d t}
\end{aligned}
$$

The voltammetric response of POT films involves two successive quasireversible redox reactions corresponding to eq (1) and (3) [48]. Only the coupling of complementary techniques allows the redox reaction in eq (2) to be discriminated. By Vis-NIR spectroscopy, the formation or elimination of all different redox species of POT can be followed at specific wavelengths [5]. However, a relationship one wavelength-one specie is not always possible since several species could contribute to the absorbance at a given wavelength in ICPs, and therefore it is necessary to select the correct wavelength for proper identification of electrochromic species. With the intention to localize the redox transitions in the potential scale, POT films were studied by using the derivative voltabsorptometric method. This method allows the potential dependence of the absorption bands to be effectively monitored by discriminating the different contributions of the overlapped signals given at close redox potentials [49].

$<$ Figure 1>

Figure 1 shows the three-dimensional (3D) surface plot of the time derivative of absorbance $\left(d A^{\lambda} / d t\right)$ between $400 \mathrm{~nm}$ and $900 \mathrm{~nm}$ together with the corresponding stable voltammogram for two forms of POT with different anionic composition (POT-NO POT-ClO - ). As it was expected, two main voltammetric peak couples are observed centered at $0.1-0.2 \mathrm{~V}$ and at $0.5-0.6 \mathrm{~V}$ depending to the anion in solution. Some mountains $\left(d A^{\lambda} / d t>0\right)$ and valleys $\left(d A^{\lambda} / d t<0\right)$ observed in the $3 \mathrm{D}$ plot coincide with the voltammetric peaks: the changes of absorbance derivative about $435 \mathrm{~nm}$, and between 700 and $900 \mathrm{~nm}$ can be associated with the more cathodic peak couple and the changes of absorbance derivative between 450 and $600 \mathrm{~nm}$ with the more anodic peak couple. In addition, the absorption band at wavelengths around $700 \mathrm{~nm}$ with maximum and minimum takes place at potentials between voltammetric peaks.

The wide range of wavelengths obtained to explain the same electrochemical transition is due to the complexity of the electrochemical system studied [50,51]. The electrochemical oxidation or reduction of film goes through $\mathrm{n}$ consecutive stoichiometric 
steps related to $\mathrm{n}$ consecutive ionization potentials where the structural composition of the polymeric backbone (single or double links, radicalization, protonation or deprotonation) and the surrounding environment (solvation and counterions) inside of film change. An example taking into account the eq (4) is given here:

$$
\begin{array}{cc}
\text { step 1) } & \langle\mathrm{P}\rangle+\mathrm{A}^{-} \rightleftarrows\left\langle\mathrm{P}^{+}, \mathrm{A}^{-}\right\rangle+\mathrm{e}^{-} \\
\text {step 2) } & \left\langle\mathrm{P}^{+}, \mathrm{A}^{-}\right\rangle+\mathrm{A}^{-} \rightleftarrows\left\langle\mathrm{P}^{2+}, 2 \mathrm{~A}^{-}\right\rangle+\mathrm{e}^{-} \\
\text {step 3) } & \left\langle\mathrm{P}^{2+}, 2 \mathrm{~A}^{-}\right\rangle+\mathrm{A}^{-} \rightleftarrows\left\langle\mathrm{P}^{3+}, 3 \mathrm{~A}^{-}\right\rangle+\mathrm{e}^{-} \\
\vdots & \\
\text { step n }) & \left\langle\mathrm{P}^{(\mathrm{n}-1)+},(\mathrm{n}-1) \mathrm{A}^{-}\right\rangle+\mathrm{A}^{-} \rightleftarrows\left\langle\mathrm{P}^{\mathrm{n}+}, \mathrm{nA}^{-}\right\rangle+\mathrm{e}^{-}
\end{array}
$$

At every step, the structure and anion composition of polymer change simultaneously involving little hypsochromic and bathochromic shifts in optical spectra [47,52]. The step 1 can be followed by the changes of absorbance at $\lambda_{1}$, the step 2 by $\lambda_{2}$ and step 3 by $\lambda_{3}$. Therefore, a single electrochemical process can be followed with a set of characteristics wavelengths. In POT films, three electrochemical processes are overlapped and this complicates the good election of interesting wavelengths. With the intention of explaining the most of the electrochemical processes in both POT forms and for practical discussions, only four wavelengths were accurately selected taking into account the bibliography and previous results [5,39,53-60]. Figure 2 shows the curves of $d A^{435 \mathrm{~nm}} / d t, d A^{810 \mathrm{~nm}} / d t, d A^{700 \mathrm{~nm}} / d t$ and $d A^{540 \mathrm{~nm}} / d t$ during the oxidation scan following the evolution of isolated polarons $(435 \mathrm{~nm})$, the coil structures of polarons when the anions interact strongly with the $\mathrm{C}=\mathrm{NH}^{+}=\mathrm{C}$ group $(810 \mathrm{~nm})$, bipolaron forms $(700 \mathrm{~nm})$ and the pernigraniline forms $(540 \mathrm{~nm})$ of POT, respectively.

In the oxidation direction for both POT forms, the peak around $0.25 \mathrm{~V}$ corresponds to the oxidation of LE form since $d A^{435 \mathrm{~nm}} / d t$ and $d A^{810 \mathrm{~nm}} / d t$ are positives, which indicate the formation of isolated polarons and the formation of coil structures, respectively. That corresponds to the oxidation semi-reaction of eq (1). Afterwards, the formation of coils structures is the principal form in POT since the isolated polarons disappears $\left(d A^{435 n m} / d t\right.$ is negative) at $0.45 \mathrm{~V}$. At the same time, bipolaron structures are formed as the positive changes of absorbance at $700 \mathrm{~nm}$ show (oxidation semireaction of eq (2)). Finally, the coil structures disappears $\left(d A^{810 n m} / d t\right.$ is negative) and the PN form appears $\left(d A^{540 n m} / d t\right.$ are positive) corresponding to the oxidation semireaction of eq (3). The formation of different structures during redox transitions of POT 
is not affected by the anion in solution since the behavior is similar than that of POT in $\mathrm{H}_{2} \mathrm{SO}_{4}$ solution in similar experimental conditions.

As it can be seen in Figure 2, only the experimental $d A^{435 \mathrm{~nm}} / d t$ curves show a typical profile due to the formation and elimination of only one specie, in this case the isolated polarons. Other experimental curves show more complexes profiles due to the overlapping of at least three electrochromic transitions. Consequently, the simplistic association between one wavelength-one electrochromic species is not always valid.

Like in current (eq (23)), the absorbance derivative at a given wavelength is the sum of the variation of the concentration considering all processes involved. So, the total absorbance derivative at $435 \mathrm{~nm}$ can be expressed as following [5]:

$$
\begin{aligned}
\left.\frac{d A_{T}^{435 n m}}{d t}\right|_{o x}= & \frac{d A_{\mathrm{LE} \rightarrow \mathrm{P}}^{435 n m}}{d t}+\frac{d A_{\mathrm{P} \rightarrow \mathrm{BP}}^{435 n m}}{d t} \\
\left.\frac{d A_{T}^{435 n m}}{d t}\right|_{\text {red }}= & \frac{d A_{\mathrm{BP} \rightarrow \mathrm{P}}^{45 n n}}{d t}+\frac{d A_{\mathrm{P} \rightarrow \mathrm{LE}}^{435 n m}}{d t}
\end{aligned}
$$

where the formation of isolated structures allows the $\mathrm{LE} \rightarrow \mathrm{P}$ transition in the oxidation directions or the $\mathrm{BP} \rightarrow \mathrm{P}$ transition in the reduction direction to be followed. On the contrary, the disappearances of these structures are related to the $\mathrm{P} \rightarrow \mathrm{BP}$ or the $\mathrm{P} \rightarrow \mathrm{LE}$ transitions.

At other selected wavelength $(\lambda=540 \mathrm{~nm}, 700 \mathrm{~nm}$ and $810 \mathrm{~nm})$, the contribution of $\mathrm{BP} \leftrightarrow \mathrm{PN}$ transitions to the total absorbance derivative must be also considered due to the mixture of species formed during the $\mathrm{n}$ redox steps (eq. (24)) .

$$
\begin{aligned}
& \left.\frac{d A_{T}^{\lambda}}{d t}\right|_{o x}=\frac{d A_{\mathrm{LE} \rightarrow \mathrm{P}}^{\lambda}}{d t}+\frac{d A_{\mathrm{P} \rightarrow \mathrm{BP}}^{\lambda}}{d t}+\frac{d A_{\mathrm{BP} \rightarrow \mathrm{PN}}^{\lambda}}{d t} \\
& \left.\frac{d A_{T}^{\lambda}}{d t}\right|_{\text {red }}=\frac{d A_{\mathrm{PN} \rightarrow \mathrm{BP}}^{\lambda}}{d t}+\frac{d A_{\mathrm{BP} \rightarrow \mathrm{P}}^{\lambda}}{d t}+\frac{d A_{\mathrm{P} \rightarrow \mathrm{LE}}^{\lambda}}{d t}
\end{aligned}
$$

$<$ Figure 2>

Accordingly, with the expression in eq (16) and the above expressions for the total absorbance derivative at these four wavelengths, we can try to fit the shape of experimental $d A^{\lambda} / d t$ curves. Figure 2 shows experimental $d A^{\lambda} / d t$ in the oxidation scan direction, which can be deconvoluted in two or three partial curves in both solutions with good results. 


\section{$\langle$ Table 1>}

As it can be seen, spectroelectrochemistry is a good technique for the full assignment of the different transitions to the color changes and in particular in this work, a better understanding of the influence of the anion size. However, a large amount of information can be obtained from this methodology. In this work, we propose to take into consideration this data complexity, not as a hindrance, but as an advantage, which will allow the influence of the nature of the anion in the solution and the effect on other transfers to be studied in depth during the electrochemical reactions of POT under potentiodynamic conditions. Table 1 collects numerical values obtained from the fitting of theses experimental curves to the model proposed by eq (16). In this case, the extinction coefficient of species at a given wavelength is unknown and for this reason, Table 1 only shows $\left(d A^{\lambda} / d t\right)_{p e a k}$.

Owing to the amount of information obtained, the deconvolution procedure allows the partial contribution of interest at a given wavelength to be hold. As it was commented above, each wavelength has been mainly associated to an electrochromic transition: $A^{435 \mathrm{~nm}}$ is associated to the formation of isolated polarons, $A^{810 \mathrm{~nm}}$ to coil structures, $A^{700 \mathrm{~nm}}$ to bipolaron forms and $A^{540 \mathrm{~nm}}$ to the pernigraniline forms of POT. Accordingly, we can discriminate the information of interest and we can study only the most interesting evolution of $d A_{\mathrm{LE}}^{435 \mathrm{P}} / d t, d A_{\mathrm{LE}}^{810 n m} / d t, d A_{\mathrm{P} \leftrightarrow \mathrm{PP}}^{700 n m} / d t$ and $d A_{\mathrm{BP} \leftrightarrow \mathrm{PN}}^{540 n m} / d t$.

As it is observed from data in Table 1, both forms of POT have remarkable differences during the electrochromic redox transitions. The separation in potential scale between the oxidation peak and the corresponding reduction peak for each electrochromic partial contribution of $d A^{\lambda} / d t$ is lower for POT-NO ${ }_{3}^{-}$(in average $30 \mathrm{mV}$ ) than $\mathrm{POT}_{-} \mathrm{ClO}_{4}^{-}$ (in average $100 \mathrm{mV}$ ). In voltammetry simulations, the peak separation is reduced when the uncompensated resistance of electrochemical system decreases [61]. The higher mobility of $\mathrm{NO}_{3}^{-}$should reduce the uncompensated resistance in the electrochemical cell reducing the peak separation contrarily to larger ions as $\mathrm{ClO}_{4}^{-}$. The lower peak separation is observed by the $\mathrm{P} \leftrightarrow \mathrm{BP}$ transitions in both POT forms $\left(d A^{710 n m} / d t\right)$. For POT-NO ${ }_{3}^{-}$, it is practically $0 \mathrm{~V}$ and for POT-ClOexpected if the $\mathrm{P} \leftrightarrow \mathrm{BP}$ transition is an "easy" structure phase transition like a reorganization of two polaronic sites to form a bipolaronic site inside of polymeric structure by means of a thermodynamic equilibrium $(2 \mathrm{P} \leftrightarrow \mathrm{BP})$. 
For each transition, an estimation of its reversibility can be obtained from the $\left(d A^{\lambda} / d t\right)_{\text {peak }}^{o x} /\left(d A^{\lambda} / d t\right)_{\text {peak }}^{\text {red }}$ ratio. In both forms of POT, the electrochromic LE $\leftrightarrow \mathrm{P}$ and $\mathrm{P} \leftrightarrow \mathrm{BP}$ transitions shows a good reversibility close to 1 at $435 \mathrm{~nm}, 810 \mathrm{~nm}$ and 700 $\mathrm{nm}$. The main difference is found in the $\mathrm{BP} \leftrightarrow \mathrm{PN}$ transitions. In $\mathrm{HClO}_{4}$ solution, POT$\mathrm{ClO}_{4}^{-}$shows a peaks ratio close to 1 . However, POT-NO $0_{3}^{-}$shows the reduction peak for the $\mathrm{PN} \rightarrow \mathrm{BP}$ transition $\left(\left(d A_{\mathrm{PN} \rightarrow \mathrm{BP}}^{540 n m} / d t\right)_{\text {peak }}^{\text {red }}\right)$ about two times higher than the oxidation peak for the $\mathrm{BP} \rightarrow \mathrm{PN}$ transition $\left(\left(d A_{\mathrm{BP} \rightarrow \mathrm{PN}}^{540 n m} / d t\right)_{\text {peak }}^{o x}\right)$.

Previous results are also in accordance with the symmetry showed for the voltammetric peak of POT in these solutions. In this last transition, $\left(b-b^{\prime}\right)$ are $70 \mathrm{~V}^{-1}$ and $53 \mathrm{~V}^{-1}$ for the POT- $\mathrm{NO}_{3}^{-}$and POT-ClOrespect to the other values, which are close to $20 \mathrm{~V}^{-1}$. From $\left(b-b^{\prime}\right)$, the width of the half height $\left(\Delta E_{p, i(1 / 2)}=\left(E_{p, i(1 / 2)}-E_{p, i(-1 / 2)}\right)\right)$ of simulated curves of all separated transitions can be calculated [62]. Based on the Frumkin-type isotherm model [41,6365], $\left(b-b^{\prime}\right)$ should be $40 \mathrm{~V}^{-1}$ for a single electron transfer at $298 \mathrm{~K}$ which correspond to a width at half height of $90.6 \mathrm{mV}$ per electron transfer $(90.6 / n \mathrm{mV})$ considering non lateral interactions between oxidized and reduced forms of structure film on working electrode during a monoelectronic transfer. $20 \mathrm{~V}^{-1}$ are considered as a classic result of this kind of films which correspond to a width at half height of $180 / n \mathrm{mV}$ (a wider peak than this one expected without interactions) $[5,66]$. This fact points to repulsive lateral interactions between random distributed electrochromic sites in permselective redox films adsorbed on an electrode. In the opposite side, the $\mathrm{PN} \rightarrow \mathrm{BP}$ transitions in both solutions present a narrower peak than this one expected without interactions $\left(\left(b-b^{\prime}\right)>40 \mathrm{~V}^{-1}\right)$. In this case, we can assume attractive interactions between electrochromic sites much more favored by the size of inserted $\mathrm{NO}_{3}^{-}$in the $\mathrm{POT}-\mathrm{NO}_{3}^{-}$form than by inserted $\mathrm{ClO}_{4}^{-}$in the POT-ClO- . Moreover, the insertion of proton during the $\mathrm{PN} \rightarrow \mathrm{BP}$ transitions also could be favored by the high concentration of protons in solution $(\mathrm{pH} \approx 0.45)$.

In spite of this, we still have some difficulties to give an exclusive explanation since alternative perspectives could be considered: the existence of a previous chemically controlled step of the single-electron transfers [67] or an apparent transfer of 0.5 electrons may also be considered with the same numerical result. 


\subsection{Voltammetric considerations}

As it was seen, the POT electrochemistry is defined by the anions exchange because they are able to modify the macromolecular structure of POT as shown by the spectroscopic results. Figure 3 shows the cyclic voltammograms of POT in both acid solutions. From spectroscopic deconvolutions, the complete electrochemical process of both POT-ClO ${ }_{4}^{-}$and POT-NO- $\mathrm{P}_{3}^{-}$forms can also be described by a sequence of three discrete but overlapped redox transitions. The redox model proposed in eq (1)-(3) can be fitted using eq (13) and (23) and taking into account the results of spectroscopic deconvolutions.

$<$ Figure 3>

Table 2 collects the values of the CV deconvolutions. Good correlations are obtained between $\mathrm{CV}$ and $d A^{\lambda} / d t$ deconvolutions. It must be taken into account that the charge flux is due to the global electrochemical reactions in the film (all $\mathrm{n}$ steps in eq (24)) and the absorbance changes at a single wavelength is due only to one specific structure of film (one step in eq (24)). Taking this into account, the couple of peaks around $0.2 \mathrm{~V}$ corresponds to the $\mathrm{LE} \leftrightarrow \mathrm{P}$ transitions (eq (1)) and the $\mathrm{BP} \leftrightarrow \mathrm{PN}$ transitions (eq (3)) are around $0.55 \mathrm{~V}$. In addition, the $\mathrm{P} \leftrightarrow \mathrm{BP}$ transitions (eq (2)) can be taken into account in the voltammogram from spectroscopic results (around $0.45 \mathrm{~V}$ ).

$<$ Table 2>

As it was expected, the size of $\mathrm{ClO}_{4}^{-}$increases the peak potential separation of $\mathrm{LE} \leftrightarrow \mathrm{P}$ and $\mathrm{BP} \leftrightarrow \mathrm{PN}$ transitions (about $140 \mathrm{mV}$ ) if it is compared with the smaller size of $\mathrm{NO}_{3}^{-}$(about $70 \mathrm{mV}$ ). Likewise, $\mathrm{P} \leftrightarrow \mathrm{BP}$ transitions are separated about $0 \mathrm{~V}$ in $\mathrm{HNO} 3$ solution and about $100 \mathrm{mV}$ in $\mathrm{HClO}_{4}$ solutions. The thermodynamic equilibrium assumed during this transitions $(2 \mathrm{P} \leftrightarrow \mathrm{BP})$ can be facilitated by the presence of smaller anions inside de polymer, as $\mathrm{NO}_{3}^{-}$does.

Table 2 also shows the surface concentration of electroactive sites $\left(\Gamma_{\max }\right)$ calculated from peak intensity (eq (13)) since the thickness of POT films is unknown. Theoretically, the same number of electroactive sites is expected to be reduced or oxidized, however, it is not observed in both POT forms. On the one hand, the amount of oxidized sites during the $\mathrm{BP} \rightarrow \mathrm{PN}$ transition is about $3.8 \mu \mathrm{mol} \mathrm{cm} \mathrm{c}^{-2}$ and on the other hand, the amount of reduced sites during the $\mathrm{PN} \rightarrow \mathrm{BP}$ transition is about $3 \mu \mathrm{mol} \mathrm{cm}{ }^{-2}$. In these electrochemical transitions, protons transfers are involved, therefore, a chemical reprotonation of recently oxidized sites (deprotonated) during the $\mathrm{BP} \rightarrow \mathrm{PN}$ transition could 
increase the charge flux necessary for a complete oxidation of film owing to the low solution $\mathrm{pH}$ [68]. Likewise, the number of reduced sites is larger (about $4.1 \mu \mathrm{mol} \mathrm{cm}{ }^{-2}$ ) than the number of oxidized sites (about $2.5 \mu \mathrm{mol} \mathrm{cm}$ ) in both POT forms for the electrochemical transitions where anions are involved (LE↔P and $\mathrm{P} \leftrightarrow \mathrm{BP}$ transitions). Therefore, the recently reduced sites during the $\mathrm{BP} \rightarrow \mathrm{P} \rightarrow \mathrm{PN}$ transition can be oxidized by oxygen in the solution, in this way, the charge flux necessary for the complete reduction of film increases. Similar experiments with higher $\mathrm{pH}$ solutions or solutions without oxygen should be necessary to confirm these assumptions. Anyway, the number of electroactive sites is similar independently of anion in solution, therefore, the structure of POT generated in $\mathrm{H}_{2} \mathrm{SO}_{4}$ solution is not a limit factor to the transfer and transport of both anions. Therefore, the properties of POT are due to the anion-structure interactions during the insertion or expulsion of anions.

\subsection{Mass evolution}

From these results, we can speculate about the transfer of species. The total mass derivative can be expressed as the sum of the mass flux due to the three transitions:

$$
\begin{gathered}
\left.\frac{d m_{T}}{d t}\right|_{o x}=\frac{d m_{\mathrm{LE} \rightarrow \mathrm{P}}}{d t}+\frac{d m_{\mathrm{P} \rightarrow \mathrm{BP}}}{d t}+\frac{d m_{\mathrm{BP} \rightarrow \mathrm{PN}}}{d t} \\
\text { and } \\
\left.\frac{d m_{T}}{d t}\right|_{\text {red }}=\frac{d m_{\mathrm{PN} \rightarrow \mathrm{BP}}}{d t}+\frac{d m_{\mathrm{BP} \rightarrow \mathrm{P}}}{d t}+\frac{d m_{\mathrm{P} \rightarrow \mathrm{LE}}}{d t}
\end{gathered}
$$

where an anion-free solvent coupling transfer in opposite directions takes place during the $\mathrm{LE} \leftrightarrow \mathrm{P}$ and $\mathrm{P} \leftrightarrow \mathrm{BP}$ transitions (exclusion effect), and protons transfer takes place during the $\mathrm{BP} \leftrightarrow \mathrm{PN}$ transitions. We tried to fit the experimental $d m / d t$ curves in both solutions taking into account eq (27) in a similar way than Figure 2 and Figure 3.

In a first approximation, if the potential peaks of deconvoluted current intensity and/or absorbance derivative are chosen (Table 1 and Table 2), four simulated curves were necessary to obtain good fittings of $d m / d t$. A new strategy to simulate the experimental mass derivative was searched. From current deconvolutions, it was assumed that all passed charge in the simulated curves of $d q / d t$ leads to the creation of redox centers. Therefore, the ionic transfer can be calculated using eq (14) [5,48]. Once obtained $d m / d t$ partial curves for the ionic transfers, the mass flux of solvent can be calculated as: 


$$
\frac{d m_{\mathrm{H}_{2} \mathrm{O}}}{d t}=\frac{d m_{T}}{d t}-\frac{d m_{\mathrm{A}^{-}}}{d t}-\frac{d m_{\mathrm{H}_{3} \mathrm{O}^{+}}}{d t}
$$

In the oxidation direction:

$$
\begin{aligned}
& \left.\frac{d m_{\mathrm{A}^{-}}}{d t}\right|_{o x}=\frac{1}{F} \delta_{\mathrm{A}^{-}} M_{\mathrm{A}^{-}}\left(\frac{d q_{\mathrm{LE} \rightarrow \mathrm{P}}}{d t}+\frac{d q_{\mathrm{P} \rightarrow \mathrm{BP}}}{d t}\right) \\
& \left.\frac{d m_{\mathrm{H}_{3} 0^{+}}}{d t}\right|_{o x}=\frac{1}{F} \delta_{\mathrm{H}_{3} 0^{+}} M_{\mathrm{H}_{3} 0^{+}}\left(\frac{d q_{\mathrm{BP} \rightarrow \mathrm{PN}}}{d t}\right)
\end{aligned}
$$

and in the reduction direction:

$$
\begin{gathered}
\left.\frac{d m_{\mathrm{A}^{-}}}{d t}\right|_{\text {red }}=\frac{1}{F} \delta_{\mathrm{A}^{-}} M_{\mathrm{A}^{-}}\left(\frac{d q_{\mathrm{BP} \rightarrow \mathrm{P}}}{d t}+\frac{d q_{\mathrm{P} \rightarrow \mathrm{LE}}}{d t}\right) \\
\text { and } \\
\left.\frac{d m_{\mathrm{H}_{3} 0^{+}}}{d t}\right|_{\text {red }}=\frac{1}{F} \delta_{\mathrm{H}_{3} \mathrm{O}^{+}} M_{\mathrm{H}_{3} \mathrm{O}^{+}}\left(\frac{d q_{\mathrm{PN} \rightarrow \mathrm{BP}}}{d t}\right)
\end{gathered}
$$

where $\delta_{\mathrm{A}^{-}}=+1$ and $\mathrm{A}^{-}$refers to both anions of this work where the molar masses are $62 \mathrm{~g}$ $\mathrm{mol}^{-1}$ and $99.5 \mathrm{~g} \mathrm{~mol}^{-1}$ for $\mathrm{NO}_{3}^{-}$and $\mathrm{ClO}_{4}^{-}$, respectively. Our previous results indicate the transfer of protons stoichiometrically accompanied by one water molecule during the $\mathrm{PN} \leftrightarrow \mathrm{BP}$ transitions $[5,40]$. Therefore, we consider $M_{\mathrm{H}_{3} \mathrm{O}^{+}}=19 \mathrm{~g} \mathrm{~mol}^{-1}$ and $\delta_{\mathrm{H}_{3} \mathrm{O}^{+}}=-1$ due to the exit of $\mathrm{H}_{3} \mathrm{O}^{+}$during the oxidation and the insertion of $\mathrm{H}_{3} \mathrm{O}^{+}$during the reduction.

\section{$<$ Figure 4>}

Figure 4 shows the thus-calculated mass fluxes during the redox cycling of POT$\mathrm{ClO}_{4}^{-}$and POT-NO- $\mathrm{NO}_{3}^{-} . d m / d t$ partial curves for $\mathrm{H}_{2} \mathrm{O}$ also show a similar profile like $d m / d t$ partial curves for the corresponding anion as it was expected if we consider the exclusion effect [69-72]. However, a slight shift can be observed (10-20 mV) between the potential peaks of $d m / d t$ partial curves of free water and anions. Structural reconfiguration owing to both the insertion/expulsion of anions and the electrochemical processes of POT are accompanied by changes in free volume of film where the free water molecules can be inserted $[73,74]$. In our model [40], the oxidation state of POT film controls the transfer of ions by charge balance but the kinetic of free water transfer is regulated by the exclusion effect of anions and the structural rearrangement of the macromolecular backbone of POT film.

Once $d m_{\mathrm{H}_{2} \mathrm{O}} / d t$ is obtained in both solutions, the partial curves may be similarly simulated using eq (14) considering two independent curves, which correspond to the electrochemical transitions where the water transfers are associated: 


$$
\begin{aligned}
& \left.\frac{d m_{\mathrm{H}_{2} \mathrm{O}}}{d t}\right|_{o x}=\left.\frac{d m_{\mathrm{H}_{2} \mathrm{O}}}{d t}\right|_{\mathrm{LE} \rightarrow \mathrm{P}}+\left.\frac{d m_{\mathrm{H}_{2} \mathrm{O}}}{d t}\right|_{\mathrm{P} \rightarrow \mathrm{BP}} \\
& \left.\frac{d m_{\mathrm{H}_{2} \mathrm{O}}}{d t}\right|_{\text {red }}=\left.\frac{d m_{\mathrm{H}_{2} \mathrm{O}}}{d t}\right|_{\mathrm{BP} \rightarrow \mathrm{P}}+\left.\frac{d m_{\mathrm{H}_{2} \mathrm{O}}}{d t}\right|_{\mathrm{P} \rightarrow \mathrm{LE}}
\end{aligned}
$$

in the oxidation direction for the $\mathrm{LE} \rightarrow \mathrm{P} \rightarrow \mathrm{BP}$ transitions and in the reduction direction for the $\mathrm{BP} \rightarrow \mathrm{P} \rightarrow \mathrm{LE}$ transitions. The quantities obtained are in Table 3 .

$<$ Table 3>

As it was expected, the total amount of water excluded by $\mathrm{ClO}_{4}^{-}$is superior to that excluded by $\mathrm{NO}_{3}^{-}$(approximately twice). Using the commercial software ChemBio3D Ultra v. 12.0 ChemBioOffice 2010, the volume of species can be estimated from the Connolly Solvent Excluded Volume. Thus, the volume of $\mathrm{NO}_{3}^{-}$is about $32 \AA^{3}$, about 47 $\AA^{3}$ for $\mathrm{ClO}_{4}^{-}$and about $10 \AA^{3}$ for $\mathrm{H}_{2} \mathrm{O}$. Taking into account this volume, about 3 water molecules can be theoretically excluded by each $\mathrm{NO}_{3}^{-}$and about 5 by each $\mathrm{ClO}_{4}^{-}$in accordance with the ratio of amount of excluded water by the anions above commented. From surface concentration calculated of anions and water molecules, a global water/anion ratio for each transition can be obtained $\left(\left|\Gamma_{\max }\right|_{\mathrm{H}_{2} \mathrm{O}} /\left|\Gamma_{\max }\right|_{\mathrm{A}^{-}}\right)$. In general, two water molecules are transferred in opposite direction in presence of $\mathrm{NO}_{3}^{-}$and about four in presence of $\mathrm{ClO}_{4}^{-}$. The mechanical expansion/contraction of POT structure during the redox processes causes lower values than the theoretical ones. The reconfiguration of POT films during the anion transfers prevents a pure exclusion effect because the volume of anions is not in accordance with the volume of excluded water molecules. In spite of this, we obtain a more dehydrated film of oxidized POT inserting $\mathrm{ClO}_{4}^{-}$that with the insertion of $\mathrm{NO}_{3}^{-}$independently of the changes of free volume inside film. Finally, $\left(b-b^{\prime}\right)$ for partial $d m_{\mathrm{H}_{2} \mathrm{O}} / d t$ is higher in the POT-NO- $\mathrm{N}_{3}^{-}$than in the POT-ClO- ${ }_{4}^{-}$in both transitions (Table 3). Therefore, the interactions owing to the transfer of anions affect the free water transfer, especially during the oxidation direction when the inserted anions are expelled from film.

\section{$<$ Figure 5>}

\subsection{Crossed functions analysis}

The crossed functions using the simulated partial curves of current, absorbance derivative and mass derivative will allow the electrochemical behavior of POT films to 
be understood in depth. Figure 6 shows the evolution of the apparent molar mass of transferred species $\left(F(d m / d q)\right.$, eq. (17)), the electrochromic efficiency $\left(F\left(d A^{\lambda} / d q\right)\right.$, eq (18)) and the mass electrochromic efficiency $\left(\left(d A^{\lambda} / d m\right)\right.$, eq (19)).

$F(d m / d q)$, was calculated considering the partial contribution of both current and mass of anions and free water by using:

$$
\frac{F\left(\frac{d m_{\mathrm{A}^{-}}}{d t}+\frac{d m_{\mathrm{H}_{2} \mathrm{O}}}{d t}\right)}{\frac{d q}{d t}}
$$

In this manner, an apparent molar mass is calculated but we can evaluate the instantaneous evolution of anion/water ratio during the cyclic voltammograms.

Moreover, we can discriminate $A^{435 \mathrm{~nm}}$ results. The changes of absorbance at 435 $\mathrm{nm}$ can also be used to analysis $\mathrm{LE} \leftrightarrow \mathrm{P}$ transitions but the formation of isolated polarons take place at initial stages of the oxidation transition and at final stages of the reduction transition. This fact is graphically observed in Figure 5 where the partial simulated curves of $\mathrm{LE} \rightarrow \mathrm{P}$ transition of POT- $\mathrm{ClO}_{4}^{-}$are showed. On the contrary, the formation of coil structures when the anions interact strongly with the $\mathrm{C}=\mathrm{NH}^{+}=\mathrm{C}$ group could take place during all these electrochemical transitions. At lower $\mathrm{pH}$, Hillman et al showed $\mathrm{a}_{3} \mathrm{O}^{+}$ release preceding the anion uptake during oxidation scan by using probe beam deflection technique and EQCM [48]. The variation of $A^{810 \mathrm{~nm}}$ in all the range of potentials confirms the only participation of anions during the LE $\leftrightarrow \mathrm{P}$ transitions in both POT forms and $d m_{\mathrm{A}^{-}} / d t$ calculated as in eq (29) and (30). Thus, only the simulated partial $d A_{\mathrm{LE} \leftrightarrow \mathrm{P}}^{810 n m} / d t$ curves was used to study the $\mathrm{LE} \leftrightarrow \mathrm{P}$ transitions, $d A_{\mathrm{P} \leftrightarrow \mathrm{BP}}^{700 n m} / d t$ to study the $\mathrm{P} \leftrightarrow \mathrm{BP}$ transitions and $d A_{\mathrm{BP} \leftrightarrow \mathrm{PN}}^{540 n m} / d t$ to study the $\mathrm{BP} \leftrightarrow \mathrm{PN}$ transitions with the electrochromic transfer functions.

\section{$<$ Figure 6>}

Figure 6a shows the crossed functions corresponding to the LE↔P transitions (with a formal potential, $E^{o \prime}$, about $0.210 \mathrm{~V}$ in $\mathrm{HNO}_{3}$ solution and about $0.170 \mathrm{~V}$ in $\mathrm{HClO}_{4}$ solution). As it is expected for the exclusion effect between anions and free water molecules, $F(d m / d q)$ shows lower values than $M_{\mathrm{NO}_{3}^{-}}$and $M_{\mathrm{ClO}_{4}^{-}}$, except for initial and final states of the formation of coil structures during these transitions because $F(d m / d q)$ tends to theoretical values of anions in both $\mathrm{POT}_{-\mathrm{NO}_{3}^{-}}$and POT-ClOMoreover, it is observed an asymmetry between the LE $\rightarrow$ PN transition (insertion of anions together with the coil structure formation) and the $\mathrm{PN} \rightarrow \mathrm{LE}$ transition (expulsion 
of anions and relaxation of the structure). In the oxidation direction, the insertion of anions in both POT forms exclude about 3 water molecules close to the peak potential of $\mathrm{LE} \rightarrow \mathrm{P}$ transition, on the contrary, the exit of $\mathrm{NO}_{3}^{-}$allow the insertion of 2 water molecules and apparently 4 water molecules for each $\mathrm{ClO}_{4}^{-}$considering a monoelectronic transfer. $F\left(d A^{810 n m} / d q\right)$ curves show a better electrochromic efficiency of POT-ClO- ${ }_{4}^{-}$than POT$\mathrm{NO}_{3}^{-}$. This fact could be due to the different anion-backbone interactions. $\mathrm{ClO}_{4}^{-}$involves a great change of color per charge unit than for $\mathrm{NO}_{3}^{-}$. However, the mass electrochromic efficiency $\left(d A^{810 n m} / d m\right)$ is higher in the POT-NO- ${ }_{3}^{-}$than POT-ClO ${ }_{4}^{-}$during $\mathrm{LE} \rightarrow \mathrm{P}$ transition owing to the smaller size of $\mathrm{NO}_{3}^{-}$. In the reduction direction, $\mathrm{POT}-\mathrm{ClO}_{4}^{-}$involves higher changes of color at $810 \mathrm{~nm}$ per mass unit than in POT-NO$-\mathrm{N}_{3}^{-}$because the mass of $\mathrm{ClO}_{4}^{-}$when this is expulsed from POT is highly compensated by the insertion of water molecules.

The $\mathrm{P} \leftrightarrow \mathrm{BP}$ transitions have a $E^{0 \prime}$ about $0.450 \mathrm{~V}$ for both POT forms (Figure $6 \mathrm{~b}$ ) owing to the structural reorganization assumed above. In this occasion, $\mathrm{ClO}_{4}^{-}$exclude one water molecule more than $\mathrm{NO}_{3}^{-}$in both transitions directions. However, one extra water molecule is excluded during the reduction transition with respect to the oxidation transition in both POT forms. As before, $F\left(d A^{700 n m} / d q\right)$ of POT-ClO- ${ }_{4}^{-}$reaches values higher than the electrochromic efficiency obtained of POT-NO- ${ }_{3}^{-}$However, the $d A^{700 n m} / d m$ is higher for the POT-ClO- during the $\mathrm{P} \rightarrow \mathrm{BP}$ transition and $d A^{700 \mathrm{~nm}} / \mathrm{dm}$ is higher for the POT- $\mathrm{NO}_{3}^{-}$during the $\mathrm{BP} \rightarrow \mathrm{P}$ transition due to the perfect mass balance between the expulsed $\mathrm{NO}_{3}^{-}$and inserted water molecules $\left(F(d m / d q)\right.$ close to $\left.0 \mathrm{~g} \mathrm{~mol}^{-1}\right)$.

The best electrochromic characteristics observed in POT films takes place at potentials of these transitions due to a higher accumulation of polaronic forms (P or BP) in the polymer lattice. The amount of P electroactive sites in the polymer can be calculated by integration of $\left(d q_{\mathrm{LE} \leftrightarrow \mathrm{P}} / d t\right)$ partial curves from the most cathodic potentials to $0.45 \mathrm{~V}$ in the oxidation direction and from the most anodic potentials up to $0.45 \mathrm{~V}$ in the reduction directions. Similarly, BP electroactive sites can be calculated from the charge of $\left(d q_{\mathrm{P} \leftrightarrow \mathrm{BP}} / d t\right)$ partial curves. In the oxidation direction, around 2-3 polarons sites per bipolaron site seems to be the conducting form of both POT forms. On the contrary, 38 bipolaron sites per polaron site are the conducting form of POT during the reduction direction for POT-NO $-\mathrm{NO}_{3}^{-}\left(16 \mathrm{BP}\right.$ per $\mathrm{P}$ for POT-ClO ${ }_{4}^{-}$). In this manner, we can offer an accurate evaluation of the percolation threshold potential where electric connection of the conducting species generates a well-connected network.[75]. This knowledge is of special 
interest for their possible technological application in sensor devices enhancing the sensitivity when the films operate in the vicinity of the percolation threshold [76]. Moreover, the mechanical reorganization of film allows a fast transfer of anions and free solvent between the film and the solution [40]. That is in accordance with molecular models showing that the fully polaronic form is a serious structural perturbation with respect to the other forms of the polymer $[77,78]$.

Finally for the $\mathrm{BP} \leftrightarrow \mathrm{PN}$ transitions, the crossed functions of $\mathrm{BP} \leftrightarrow \mathrm{PN}$ transitions are showed in Figure $6 \mathrm{c}$ with a $E^{0 \prime}$ about $0.50 \mathrm{~V}$ in both solutions. $F(d m / d q)$ is constantly $-19 \mathrm{~g} \mathrm{~mol}^{-1}$ during the $\mathrm{BP} \leftrightarrow \mathrm{PN}$ transitions owing to the assumed model where the hydrated protons are the only cation necessary to the protonation/deprotonation of POT during these transitions. The electrochromic efficiencies show similar values in both POT forms but lower than the efficiencies in other redox transitions. In general, both anions do not affect the proton transfer and, in consequence, the electrochemistry of $\mathrm{BP} \leftrightarrow \mathrm{PN}$ transitions. However, the peak potential of $\mathrm{PN} \rightarrow \mathrm{BP}$ transition of $\mathrm{POT}_{-} \mathrm{ClO}_{4}^{-}$is close to $0.4 \mathrm{~V}$. The tetrahedral molecular geometry of $\mathrm{ClO}_{4}^{-}$inserted in POT during the oxidation reactions could affect the insertion of protons during this redox transition.

By cyclic spectroelectrogravimetry, both forms of POT are intensively compared and specific differences can be observed during the oxidation and reduction reactions of films. The cyclic spectroelectrogravimetry provides a more complete analysis of POT electrochemistry than spectroelectrochemistry techniques or EQCM. Color changer or, in other words, structural changes of polymers can be correlated with mass changes owing to the species transfers during the electrochemical reactions. In this manner, we can neglect temporal structural changes caused by sequential experiments (history effects) and the findings shown here would be much more difficult to achieve.

\section{CONCLUSION}

The combination of several techniques in situ allows electrochemically complex materials to be described in depth. The complementarity of voltammetry, electrogravimetry and Vis-NIR spectra (cyclic spectroelectrogravimetry) allows the three electrochemical transitions of POT films to be separated. This analysis has been done in two monoprotic acid solutions. The size of anions plays an important role causing new electrochemical properties of the hosting film because they interact with the molecular structure of film. During the $\mathrm{P} \leftrightarrow \mathrm{BP}$ transitions, the internal reorganization of species 
could improve the transfer of species maybe by repulsion forces between electrically charged species (anions, cations and polaronic/bipolaronic forms of POT) enhancing simultaneously the electronic conductance of POT. This fact could explain the results of $\left(b-b^{\prime}\right)$ around $20 \mathrm{~V}^{-1}$ taking into account the Frumkin-type isotherm. Better electrochromic behaviors are observed during these transitions of both POT forms. However, the electrochromic properties of POT depend on the direction of anions transfer. Better electrochromic efficiencies $\left(F\left(d A^{\lambda} / d q\right)\right)$ are observed for POT-ClOduring the oxidation $\mathrm{LE} \rightarrow \mathrm{P} \rightarrow \mathrm{BP}$ transitions (anion insertion) and better mass electrochromic efficiencies $\left(d A^{\lambda} / d m\right)$ are observed for POT- $\mathrm{NO}_{3}^{-}$during the reduction $\mathrm{BP} \rightarrow \mathrm{P} \rightarrow \mathrm{LE}$ transitions (anion expulsion). Moreover, the size of inserted $\mathrm{ClO}_{4}^{-}$may be the main problem for the protonation of POT during the $\mathrm{PN} \rightarrow \mathrm{BP}$ transition. On the other hand, $\mathrm{ClO}_{4}^{-}$is able to exclude more water molecules than $\mathrm{NO}_{3}^{-}$, which allows the formation of less hydrated films if they are oxidized in spite of the structure reorganization during the $\mathrm{LE} \leftrightarrow \mathrm{P} \leftrightarrow \mathrm{BP}$ transitions.

The application of the crossed functions analysis allows these changes and processes to be analyzed separately in situ during a cyclic voltammetry experiment minimizing possible errors due to the different history of the films if a sequential analysis is done. This information opens new perspectives mainly for the development of new methodologies allowing a better evaluation and understanding of ion insertion and structural changes in the conducting POT and more widely in other electroactive materials, which can be used for specific tailoring of signal transducer devices. In the future, it can contribute to the development of some devices in the better electrochemical conditions such as smart ion-high selective electrodes.

\section{ACKNOWLEDGMENTS}

Part of this work was supported by CICyT project CTQ2011-28973/BQU. J. A. acknowledges his position to the Ajuntament de València.

\section{REFERENCES}

[1] R.J. Mortimer, Spectroelectrochemistry, Methods and Instrumentation, in: John Lindon (Ed.), Encyclopedia of Spectroscopy and Spectrometry (Second Edition), Academic Press, Oxford, 1999: pp. 2633-2639. 
[2] R.J. Mortimer, Spectroelectrochemistry, Applications, in: John Lindon (Ed.), Encyclopedia of Spectroscopy and Spectrometry (Second Edition), Academic Press, Oxford, 1999: pp. 2620-2632.

[3] W.A. Marmisolle, D. Posadas, M.I. Florit, Electrochemical aging of poly(aniline) and its ring substituted derivatives, J. Phys. Chem. B. 112 (2008) 10800-10805.

[4] T. Otero, H. Grande, J. Rodriguez, A New Model for Electrochemical Oxidation of Polypyrrole Under Conformational Relaxation Control, J. Electroanal. Chem. 394 (1995) 211-216.

[5] J. Agrisuelas, C. Gabrielli, J.J. García-Jareño, H. Perrot, F. Vicente, Kinetic and Mechanistic Aspects of a Poly(o-toluidine)-Modified Gold Electrode. 1. Simultaneous Cyclic Spectroelectrochemistry and Electrogravimetry Studies in H2SO4 Solutions, J. Phys. Chem. C. 116 (2012) 15620-15629.

[6] C.-Y. Chung, T.-C. Wen, A. Gopalan, Identification of electrochromic sites in poly(diphenylamine) using a novel absorbance-potential-wavelength profile, Electrochim. Acta. 47 (2001) 423-431.

[7] J. Agrisuelas, D. Giménez-Romero, J.J. García-Jareño, F. Vicente, Vis/NIR spectroelectrochemical analysis of poly-(Azure A) on ITO electrode, Electrochem. Commun. 8 (2006) 549-553.

[8] G. Inzelt, M. Pineri, J.W. Schultze, M.A. Vorotyntsev, Electron and proton conducting polymers: recent developments and prospects, Electrochim. Acta. 45 (2000) 2403-2421.

[9] G. Inzelt, Mechanism of Charge Transport in Polymer Modified Electrodes, in: Bard, A. J. (Ed.), Electroanalytical Chemistry, A Series of Advances, Marcel Dekker, Inc., New York, 1993: pp. 89-241.

[10] R.W. Murray, Molecular Design of Electrode Surfaces, Wiley-Blackwell, New York, 1992.

[11] M.E.G. Lyons, Electroactive Polymer Electrochemistry, Part 1: Fundamentals, 1st ed., Springer, New York, 1995.

[12] M.E.G. Lyons, Electroactive Polymer Electrochemistry: Part 2: Methods and Applications, Springer, 1996.

[13] Foster, R. J., Vos, J. G., Theory and Analytical Applications of Modified Electrodes, in: G. Svehla (Ed.), Comprehensive Analytical Chemistry, Elsevier Science Ltd, Amsterdam, 1992: p. 524.

[14] S.R. Forrest, M.E. Thompson, Introduction: Organic Electronics and Optoelectronics, Chem. Rev. 107 (2007) 923-925.

[15] K. Yoshikawa, K. Yoshioka, A. Kitani, K. Sasaki, Preparation of highly conducting polyanilines, J. Electroanal. Chem. 270 (1989) 421-427.

[16] J. Yano, M. Kobayashi, S. Yamasaki, Y. Harima, K. Yamashita, Mean redox potentials of polyaniline determined by chronocoulometry, Synth. Met. 119 (2001) 315-316.

[17] G. Sonmez, Polymeric electrochromics, Chem. Commun. (2005) 5251-5259.

[18] R.J. Mortimer, A.L. Dyer, J.R. Reynolds, Electrochromic organic and polymeric materials for display applications, Displays. 27 (2006) 2-18.

[19] J.M. Bauldreay, M.D. Archer, Dye-modified electrodes for photogalvanic cells, Electrochim. Acta. 28 (1983) 1515-1522.

[20] S. Ashley, Artificial Muscles, Sci. Am. 289 (2003) 52-59.

[21] T.F. Otero, J.M. Sansinena, Bilayer dimensions and movement in artificial muscles, Bioelectrochem. Bioenerg. 42 (1997) 117-122.

[22] Q. Pei, G. Yu, C. Zhang, Y. Yang, A.J. Heeger, Polymer Light-Emitting Electrochemical Cells, Science. 269 (1995) 1086-1088. 
[23] L. Edman, Bringing light to solid-state electrolytes: The polymer light-emitting electrochemical cell, Electrochim. Acta. 50 (2005) 3878-3885.

[24] T. Selvaraju, R. Ramaraj, Simultaneous determination of ascorbic acid, dopamine and serotonin at poly(phenosafranine) modified electrode, Electrochem. Commun. 5 (2003) 667-672.

[25] Y. Wang, S. Hu, A novel nitric oxide biosensor based on electropolymerization poly(toluidine blue) film electrode and its application to nitric oxide released in liver homogenate, Biosens. Bioelectron. 22 (2006) 10-17.

[26] C.M.A. Brett, G. Inzelt, V. Kertesz, Poly(methylene blue) modified electrode sensor for haemoglobin, Anal. Chim. Acta. 385 (1999) 119-123.

[27] A.A. Karyakin, E.E. Karyakina, W. Schuhmann, H.-L. Schmidt, Electropolymerized Azines: Part II. In a Search of the Best Electrocatalyst of NADH Oxidation, Electroanalysis. 11 (1999) 553-557.

[28] S.-M. Chen, K.-C. Lin, The electrocatalytic properties of polymerized neutral red film modified electrodes, J. Electroanal. Chem. 511 (2001) 101-114.

[29] C.M. Moore, S.D. Minteer, R.S. Martin, Microchip-based ethanol/oxygen biofuel cell, Lab Chip. 5 (2005) 218-225.

[30] N.L. Akers, C.M. Moore, S.D. Minteer, Development of alcohol/O2 biofuel cells using salt-extracted tetrabutylammonium bromide/Nafion membranes to immobilize dehydrogenase enzymes, Electrochim. Acta. 50 (2005) 2521-2525.

[31] V. Bavastrello, S. Carrara, M.K. Ram, C. Nicolini, Optical and Electrochemical Properties of Poly(o-toluidine) Multiwalled Carbon Nanotubes Composite Langmuir-Schaefer Films, Langmuir. 20 (2004) 969-973.

[32] Y.Z. Wang, J. Joo, C.-H. Hsu, J.P. Pouget, A.J. Epstein, Charge Transport of Hydrochloric Acid Doped Polyaniline and Poly(o-toluidine) Fibers: Role of Processing, Macromolecules. 27 (1994) 5871-5876.

[33] P. Ocon, L. Vazquez, R.C. Salvarezza, A.J. Arvia, P. Herrasti, J.M. Vara, Scanning Tunneling Microscopy Fractal Characterization of Poly(o-toluidine) Films Produced Electrochemically on Polyfaceted Gold Single Crystal Spheres, J. Phys. Chem. 98 (1994) 2418-2425.

[34] J.A. Osaheni, S.A. Jenekhe, H. Vanherzeele, J.S. Meth, Third-order nonlinear optical properties of thin films of polyanilines and poly(o-toluidines), Chem. Mater. 3 (1991) 218-221.

[35] M. J. Henderson, A. Robert Hillman, E. Vieil, A combined electrochemical quartz crystal microbalance (EQCM) and probe beam deflection (PBD) study of a poly(otoluidine) modified electrode in perchloric acid solution, J. Electroanal. Chem. 454 (1998) 1-8.

[36] M.J. Henderson, A.R. Hillman, E. Vieil, Chronoamperometric resolution of ion and solvent transfers at a poly(o-toluidine) modified electrode by combined electrochemical quartz crystal microbalance (EQCM) and probe beam deflection (PBD), Electrochim. Acta. 45 (2000) 3885-3894.

[37] A.R. Hillman, L. Bailey, A. Glidle, J.M. Cooper, N. Gadegaard, J.R.P. Webster, Spatial distributions of polymer and mobile species in poly(o-toluidine) films, J. Electroanal. Chem. 532 (2002) 269-276.

[38] Q. Yang, Y. Zhang, H. Li, Y. Zhang, M. Liu, J. Luo, et al., Electrochemical copolymerization study of o-toluidine and o-aminophenol by the simultaneous EQCM and in situ FTIR spectroelectrochemisty, Talanta. 81 (2010) 664-672.

[39] S. Bilal, A.-H.A. Shah, R. Holze, A correlation of electrochemical and spectroelectrochemical properties of poly(o-toluidine), Electrochim. Acta. 54 (2009) 4851-4856. 
[40] J. Agrisuelas, C. Gabrielli, J.J. García-Jareño, H. Perrot, F. Vicente, Kinetic and Mechanistic Aspects of a Poly(o-Toluidine)-Modified Gold Electrode. 2.

Alternating Current Electrogravimetry Study in H2SO4 Solutions, J. Phys. Chem. C. 116 (2012) 15630-15640.

[41] Allen J. Bard, Larry R. Faulkner, Electrochemical Methods: Fundamentals and Applications, 2nd Edition, Wiley-Blackwell, New York, 2001.

[42] A. Rubin, H. Perrot, C. Gabrielli, M.C. Pham, B. Piro, Electrochemical and electrogravimetric behaviors of conducting polymer. Theoretical aspects and application to co-polymer films based on juglone, Electrochim. Acta. 55 (2010) 6136-6146.

[43] A.R. Hillman, S.J. Daisley, S. Bruckenstein, Ion and solvent transfers and trapping phenomena during n-doping of PEDOT films, Electrochim. Acta. 53 (2008) 3763-3771.

[44] C. Gabrielli, M. Keddam, N. Nadi, H. Perrot, Ions and solvent transport across conducting polymers investigated by ac electrogravimetry. Application to polyaniline, J. Electroanal. Chem. 485 (2000) 101-113.

[45] C. Gabrielli, J.J. García-Jareño, M. Keddam, H. Perrot, F. Vicente, AcElectrogravimetry Study of Electroactive Thin Films. I. Application to Prussian Blue, J. Phys. Chem. B. 106 (2002) 3182-3191.

[46] D. Benito, C. Gabrielli, J.J. García-Jareño, M. Keddam, H. Perrot, F. Vicente, Study by EQCM on the voltammetric electrogeneration of poly(neutral red). The effect of the $\mathrm{pH}$ and the nature of cations and anions on the electrochemistry of the films, Electrochim. Acta. 48 (2003) 4039-4048.

[47] W.A. Gazotti Jr., M.J.D.M. Jannini, S.I. Córdoba de Torresi, M.-A. De Paoli, Influence of dopant, $\mathrm{pH}$ and potential on the spectral changes of poly(omethoxyaniline): relationship with the redox processes, J. Electroanal. Chem. 440 (1997) 193-199.

[48] M.J. Henderson, A.R. Hillman, E. Vieil, Ion and solvent transfer discrimination at a poly(o-toluidine) film exposed to $\mathrm{HClO} 4$ by combined electrochemical quartz crystal microbalance (EQCM) and probe beam deflection (PBD), J. Phys. Chem. B. 103 (1999) 8899-8907.

[49] J.I. Son, J. Hwang, S.-H. Jin, Y.-B. Shim, The determination of the redox potentials of the radical species of a conductive polymer with a spectroelectrochemical technique, J. Electroanal. Chem. 628 (2009) 16-20.

[50] T.F. Otero, I. Boyano, Nucleation and nonstoichiometry in electrochromic conducting polymers, ChemPhysChem. 4 (2003) 868-872.

[51] T.F. Otero, Biomimetic Conducting Polymers: Synthesis, Materials, Properties, Functions, and Devices, Polym. Rev. 53 (2013) 311-351.

[52] J. Lopez-Palacios, E. Munoz, M. Aranzazu Heras, A. Colina, V. Ruiz, Study of polyaniline films degradation by thin-layer bidimensional spectroelectrochemistry, Electrochim. Acta. 52 (2006) 234-239.

[53] G. Zhang, A. Zhang, X. Liu, S. Zhao, J. Zhang, J. Lu, Investigation of the electropolymerization of o-toluidine and p-phenylenediamine and their electrocopolymerization by in situ ultraviolet-visible spectroelectrochemistry, J. Appl. Polym. Sci. 115 (2010) 2635-2647.

[54] A. Elmansouri, A. Outzourhit, A. Lachkar, N. Hadik, A. Abouelaoualim, M.E. Achour, et al., Influence of the counter ion on the properties of poly(o-toluidine) thin films and their Schottky diodes, Synth. Met. 159 (2009) 292-297. 
[55] S. Shreepathi, R. Holze, Spectroelectrochemical Investigations of Soluble Polyaniline Synthesized via New Inverse Emulsion Pathway, Chem. Mater. 17 (2005) 4078-4085.

[56] M.R. Nabid, A.A. Entezami, Enzymatic synthesis and characterization of a watersoluble, conducting poly(o-toluidine), Eur. Polym. J. 39 (2003) 1169-1175.

[57] E.M. Andrade, F.V. Molina, M.I. Florit, D. Posadas, IR response of poly(otoluidine) : spectral modifications upon redox state change, J. Electroanal. Chem. 419 (1996) 15-21.

[58] S. Bilal, R. Holze, In situ UV-vis spectroelectrochemistry of poly(ophenylenediamine-co-m-toluidine), Electrochim. Acta. 52 (2007) 5346-5356.

[59] B.J. Johnson, S.-M. Park, Electrochemistry of Conductive Polymer XIX. Oxidation of Aniline at Bare and Polyaniline-Modified Platinum Electrodes Studied by Electrochemical Impedance Spectroscopy, J. Electrochem. Soc. 143 (1996) 1269-1276.

[60] R.M.Q. Mello, R.M. Torresi, S.I. Córdoba de Torresi, E.A. Ticianelli, Ellipsometric, Electrogravimetric, and Spectroelectrochemical Studies of the Redox Process of Sulfonated Polyaniline, Langmuir. 16 (2000) 7835-7841.

[61] J.J. Garcia-Jareño, J. Navarro-Laboulais, F. Vicente, A numerical approach to the voltammograms of the reduction of Prussian Blue films on ITO electrodes, Electrochim. Acta. 42 (1997) 1473-1480.

[62] J. Agrisuelas, C. Gabrielli, J.J. Garcia-Jareno, D. Gimenez-Romero, H. Perrot, F. Vicente, Spectroelectrochemical identification of the active sites for protons and anions insertions into poly-(Azure a) thin polymer films, J. Phys. Chem. C. 111 (2007) 14230-14237.

[63] A.N. Frumkin, B.B. Damaskin, Adsorption of organic compounds at electrodes, in: B.E. Conway (Ed.), Modern Aspects of Electrochemistry, Butterworth, London, 1964: pp. 149-223.

[64] E. Laviron, The use of linear potential sweep voltammetry and of a.c. voltammetry for the study of the surface electrochemical reaction of strongly adsorbed systems and of redox modified electrodes, J. Electroanal. Chem. 100 (1979) 263-270.

[65] J. Redepenning, B. Miller, S. Burnham, Reversible Voltammetric Response of Electrodes Coated with Permselective Redox Films, Anal. Chem. 66 (1994) 15601565 .

[66] J. Agrisuelas, J.J. García-Jareño, D. Gimenez-Romero, F. Vicente, An approach to the electrochemical activity of poly-(phenothiazines) by complementary electrochemical impedance spectroscopy and Vis-NIR spectroscopy, Electrochim. Acta. 55 (2010) 6128-6135.

[67] F. Vicente, M.A. Núñez-Flores, C. Sanz, Kalousek polarographic study of paludrine and chlorhexidine hydrochlorides, Electrochim. Acta. 30 (1985) 17231725 .

[68] J. Stejskal, J. Prokes, M. Trchova, Reprotonation of polyaniline: A route to various conducting polymer materials, React. Funct. Polym. 68 (2008) 1355-1361.

[69] J. Agrisuelas, C. Gabrielli, J.J. Garcia-Jareno, H. Perrot, F. Vicente, Ionic and Free Solvent Motion in Poly(azure A) Studied by ac-Electrogravimetry, J. Phys. Chem. C. 115 (2011) 11132-11139.

[70] W. Plieth, A. Bund, U. Rammelt, S. Neudeck, L.M. Duc, The role of ion and solvent transport during the redox process of conducting polymers, Electrochim. Acta. 51 (2006) 2366-2372. 
[71] A. Hillman, D. Loveday, M. Swann, S. Bruckenstein, C. Wilde, Transport of Neutral Species in Electroactive Polymer-Films, J. Chem. Soc.-Faraday Trans. 87 (1991) 2047-2053.

[72] A. Hillman, D. Loveday, M. Swann, S. Bruckenstein, C. Wilde, Mobile Species Uptake by Polymer-Modified Electrodes, Analyst. 117 (1992) 1251-1257.

[73] A. Hillman, S. Bruckenstein, Role of Film History and Observational Timescale on Redox Switching Kinetics of Electroactive Films .1. a New Model for Permselective Films with Polymer Relaxation Processes, J. Chem. Soc.-Faraday Trans. 89 (1993) 339-348.

[74] I. Jureviciute, S. Bruckenstein, A. Jackson, A.R. Hillman, Redox history effects accompanying the electrochemical cycling of poly(vinylferrocene), J. Solid State Electrochem. 8 (2004) 403-410.

[75] J. Cao, K. Aoki, Percolation threshold potentials at quasi-static electrochemical switching of polyaniline films, Electrochim. Acta. 41 (1996) 1787-1792.

[76] E. Bekyarova, I. Kalinina, M.E. Itkis, L. Beer, N. Cabrera, R.C. Haddon, Mechanism of ammonia detection by chemically functionalized single-walled carbon nanotubes: In situ electrical and optical study of gas analyte detection, J. Am. Chem. Soc. 129 (2007) 10700-10706.

[77] J.N. Petrova, J.R. Romanova, G.K. Madjarova, A.N. Ivanova, A.V. Tadjer, Fully Doped Oligomers of Emeraldine Salt: Polaronic versus Bipolaronic Configuration, J. Phys. Chem. B. 115 (2011) 3765-3776.

[78] W.S. Huang, A.G. Macdiarmid, Optical-Properties of Polyaniline, Polymer. 34 (1993) 1833-1845. 


\section{TABLES}

Table 1. Parameters obtained from the fitting of experimental absorbance derivative curves to eq (16) and eq (26) in Figure 2.

\section{$\mathrm{HNO}_{3}$ solution}

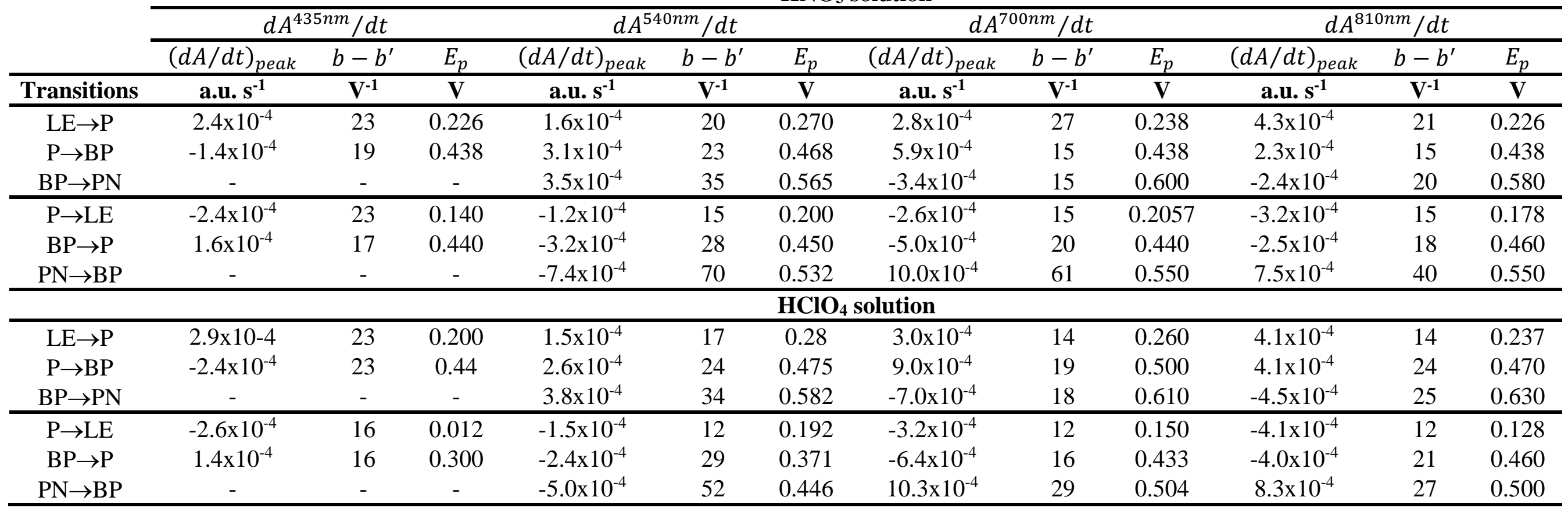


Table 2. Parameters obtained from the fitting of experimental voltammetric curves to eq.

(13) in Figure 3.

\begin{tabular}{lcccccc}
\cline { 2 - 7 } & \multicolumn{3}{c}{ HNO $_{3}$ solution } & \multicolumn{3}{c}{ HClO $_{\mathbf{4}}$ solution } \\
\cline { 2 - 7 } Transitions & $\left|\Gamma_{\text {max }}\right|$ & $b-b^{\prime}$ & $E_{p}$ & $\left|\Gamma_{\text {max }}\right|$ & $b-b^{\prime}$ & $E_{p}$ \\
& $\mu \mathbf{m o l ~ c m}^{-2}$ & $\mathbf{V}^{-1}$ & $\mathbf{V}$ & $\mu \mathbf{m o l ~ c m}^{-2}$ & $\mathbf{V}^{-\mathbf{1}}$ & $\mathbf{V}$ \\
\hline $\mathrm{LE} \rightarrow \mathrm{P}$ & 2.3 & 25 & 0.259 & 2.9 & 18 & 0.245 \\
$\mathrm{P} \rightarrow \mathrm{BP}$ & 2.3 & 15 & 0.460 & 2.8 & 16 & 0.480 \\
$\mathrm{BP} \rightarrow \mathrm{PN}$ & 4.3 & 17 & 0.570 & 3.3 & 25 & 0.605 \\
\hline $\mathrm{P} \rightarrow \mathrm{LE}$ & 3.7 & 15 & 0.172 & 4.9 & 12 & 0.097 \\
$\mathrm{BP} \rightarrow \mathrm{P}$ & 4.4 & 18 & 0.457 & 3.7 & 13 & 0.378 \\
$\mathrm{PN} \rightarrow \mathrm{BP}$ & 3.2 & 52 & 0.521 & 2.7 & 33 & 0.471 \\
\hline
\end{tabular}


Table 3. Parameters used in the simulated curves of $d m / d t$ for $\mathrm{H}_{2} \mathrm{O}$ using eq (31) from the data of Figure 4.

\begin{tabular}{lcccccc}
\cline { 2 - 7 } & \multicolumn{3}{c}{$\mathbf{H N O}_{\mathbf{3}}$ solution } & \multicolumn{3}{c}{ HClO $_{\mathbf{4}}$ solution } \\
\cline { 2 - 7 } Transitions & $\left|\Gamma_{\text {max }}\right|$ & $b-b^{\prime}$ & $E_{p}$ & $\left|\Gamma_{\text {max }}\right|$ & $b-b^{\prime}$ & $E_{p}$ \\
$\mathbf{m m o l ~ c m}^{-\mathbf{2}}$ & $\mathbf{V}^{-\mathbf{1}}$ & $\mathbf{V}$ & $\mu \mathbf{m o l ~ c m}^{-\mathbf{2}}$ & $\mathbf{V}^{-\mathbf{1}}$ & $\mathbf{V}$ \\
\hline $\mathrm{LE} \rightarrow \mathrm{P}$ & 4.8 & 31 & 0.245 & 5.1 & 28 & 0.224 \\
$\mathrm{P} \rightarrow \mathrm{BP}$ & 1.6 & 33 & 0.485 & 10.8 & 17 & 0.495 \\
\hline $\mathrm{P} \rightarrow \mathrm{LE}$ & 5.6 & 20 & 0.155 & 18.6 & 13 & 0.090 \\
$\mathrm{BP} \rightarrow \mathrm{P}$ & 13.2 & 21 & 0.457 & 13.9 & 14 & 0.370 \\
\hline
\end{tabular}




\section{FIGURES LEGENDS}

Figure 1. 3D surface of the $d A^{\lambda} / d t$-potential-wavelength for the gold electrode modified by POT in $.5 \mathrm{M} \mathrm{HNO}_{3}$ (a) and $0.5 \mathrm{M} \mathrm{HClO}_{4}$ (b) and corresponding cyclic voltammogram performed with a $100 \mathrm{mV} \mathrm{s}^{-1}$ potential scan rate. Eleven Vis-NIR spectra were collected each second. The mountains (solid lines) and valleys (dotted lines) of both profiles represent increasing $\left(d A^{\lambda} / d t>0\right)$ and decreasing $\left(d A^{\lambda} / d t<0\right)$ regions of absorbance, respectively.

Figure 2. Experimental and simulated curves of $d A^{\lambda} / d t$ at $435 \mathrm{~nm}$, at $540 \mathrm{~nm}$, at $700 \mathrm{~nm}$ and at $810 \mathrm{~nm}$ using eq (16) with the parameters given in Table 1 for the change of absorbance of the gold electrode modified by POT in $0.5 \mathrm{M} \mathrm{HNO}_{3}$ (a) and $0.5 \mathrm{M} \mathrm{HClO}_{4}$ (b) with a $100 \mathrm{mV} \mathrm{s}^{-1}$ potential scan rate.

Figure 3. Cyclic voltammogram of POT performed at $100 \mathrm{mV} \mathrm{s}^{-1}$ scan rate of POT gold modified electrode in $0.5 \mathrm{M} \mathrm{HNO}_{3}$ (a) and $0.5 \mathrm{M} \mathrm{HClO}_{4}$ (b). The parameters of simulated curves are in Table 2 using eq (13)

Figure 4. Experimental and simulated curves of $d m / d t$ using eq (14) with the parameters given in Table 3 (inset in (a)), for the cyclic voltammetry of gold electrode modified by POT in $0.5 \mathrm{M} \mathrm{HNO}_{3}$ (a) and $0.5 \mathrm{M} \mathrm{HClO}_{4}$ (b) with a $100 \mathrm{mV} \mathrm{s}^{-1}$ potential scan rate.

Figure 5. $d q / d t, d A^{435 \mathrm{~nm}} / d t$ and $d A^{800 \mathrm{~nm}} / d t$ partial curves corresponding to the $\mathrm{LE} \rightarrow \mathrm{P}$ transition of POT in $0.5 \mathrm{M} \mathrm{HClO}_{4}$ solution using the parameters in Table 1 and Table 2 for simulation by eq (13) and (16).

Figure 6. Crossed functions on potential scale for POT in $0.5 \mathrm{M} \mathrm{HNO}_{3}$ (circles) and 0.5 $\mathrm{M} \mathrm{HClO}_{4}$ (squares) in the oxidation (open symbols) and reduction (closed symbols) direction of potential scan for the $\mathrm{LE} \leftrightarrow \mathrm{P}$ transitions at $810 \mathrm{~nm}$ (a), the $\mathrm{P} \leftrightarrow \mathrm{BP}$ transitions at $700 \mathrm{~nm}(\mathrm{~b})$ and $\mathrm{BP} \leftrightarrow \mathrm{PN}$ transitions at $540 \mathrm{~nm}(\mathrm{c})$. 


\section{FIGURES}

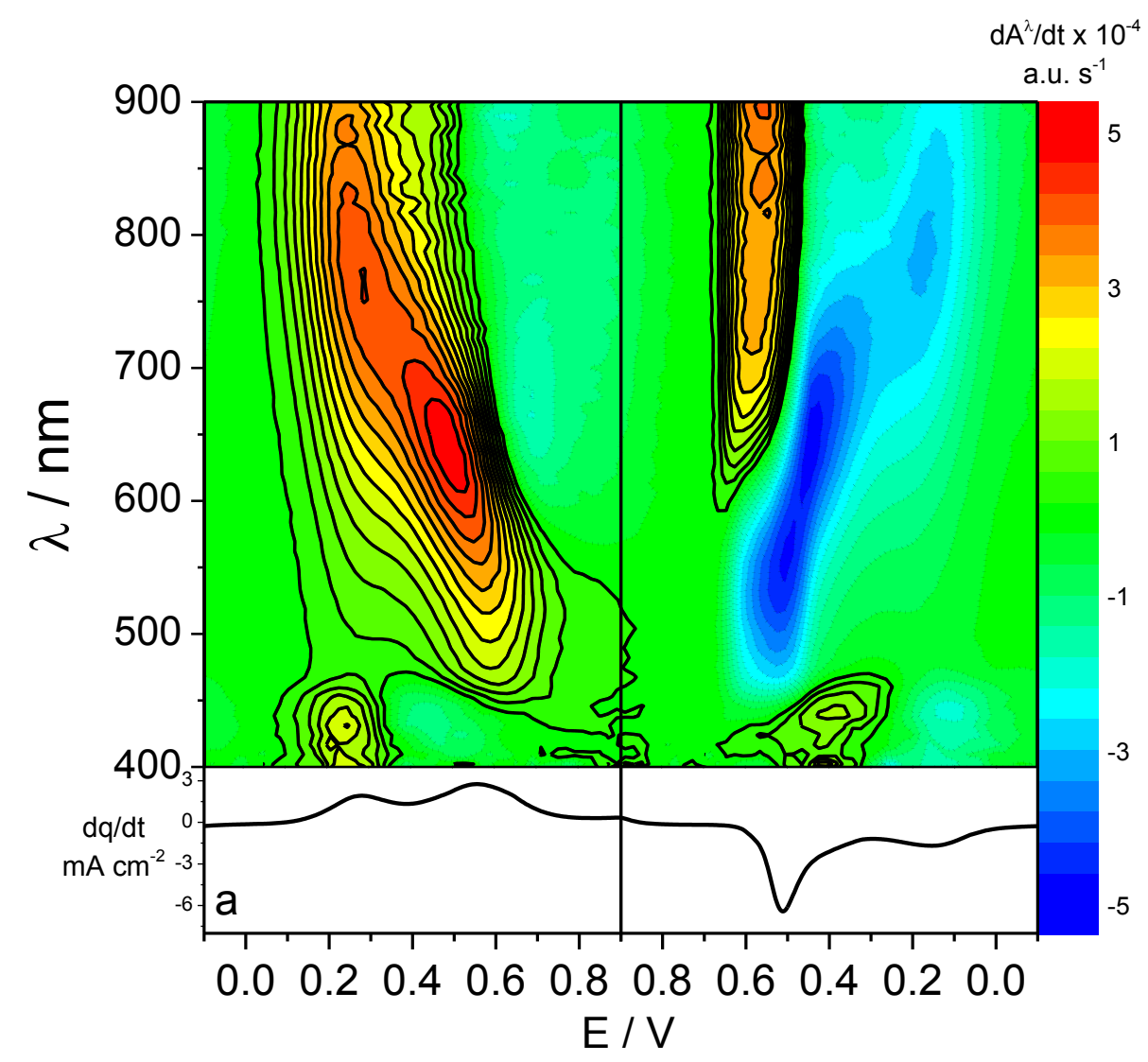

Figure 1a 


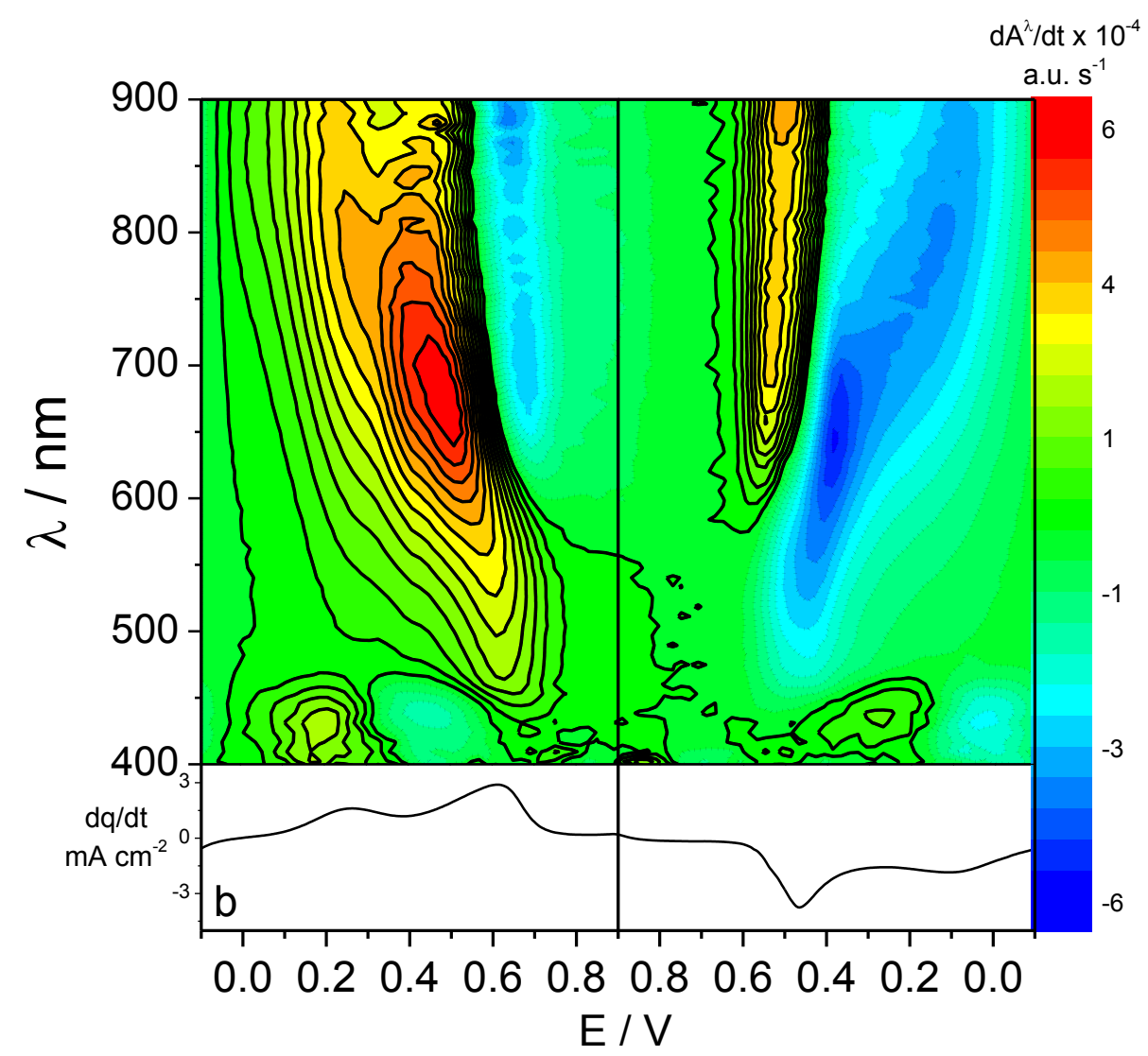

Figure 1b 


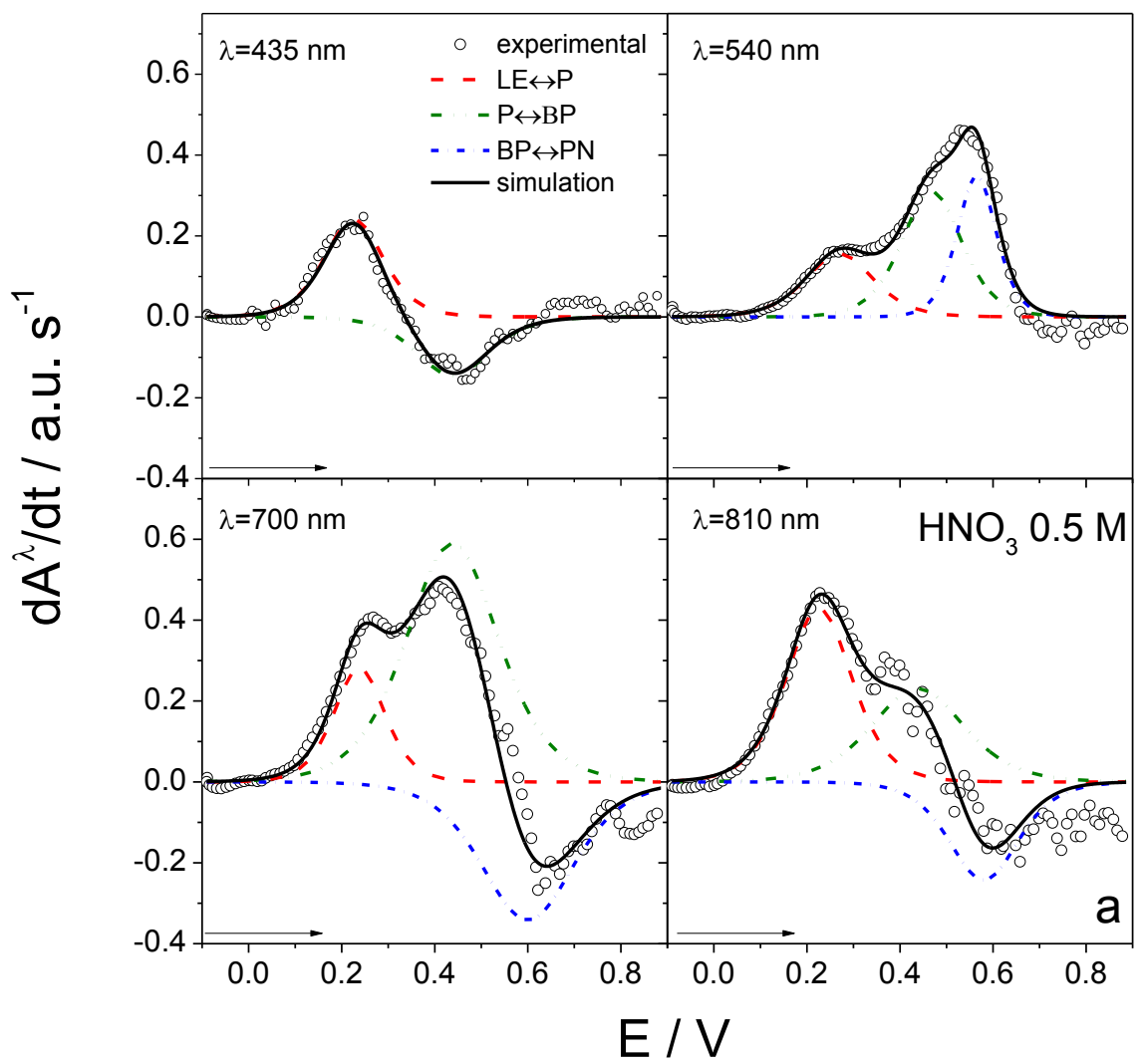

Figure 2a 


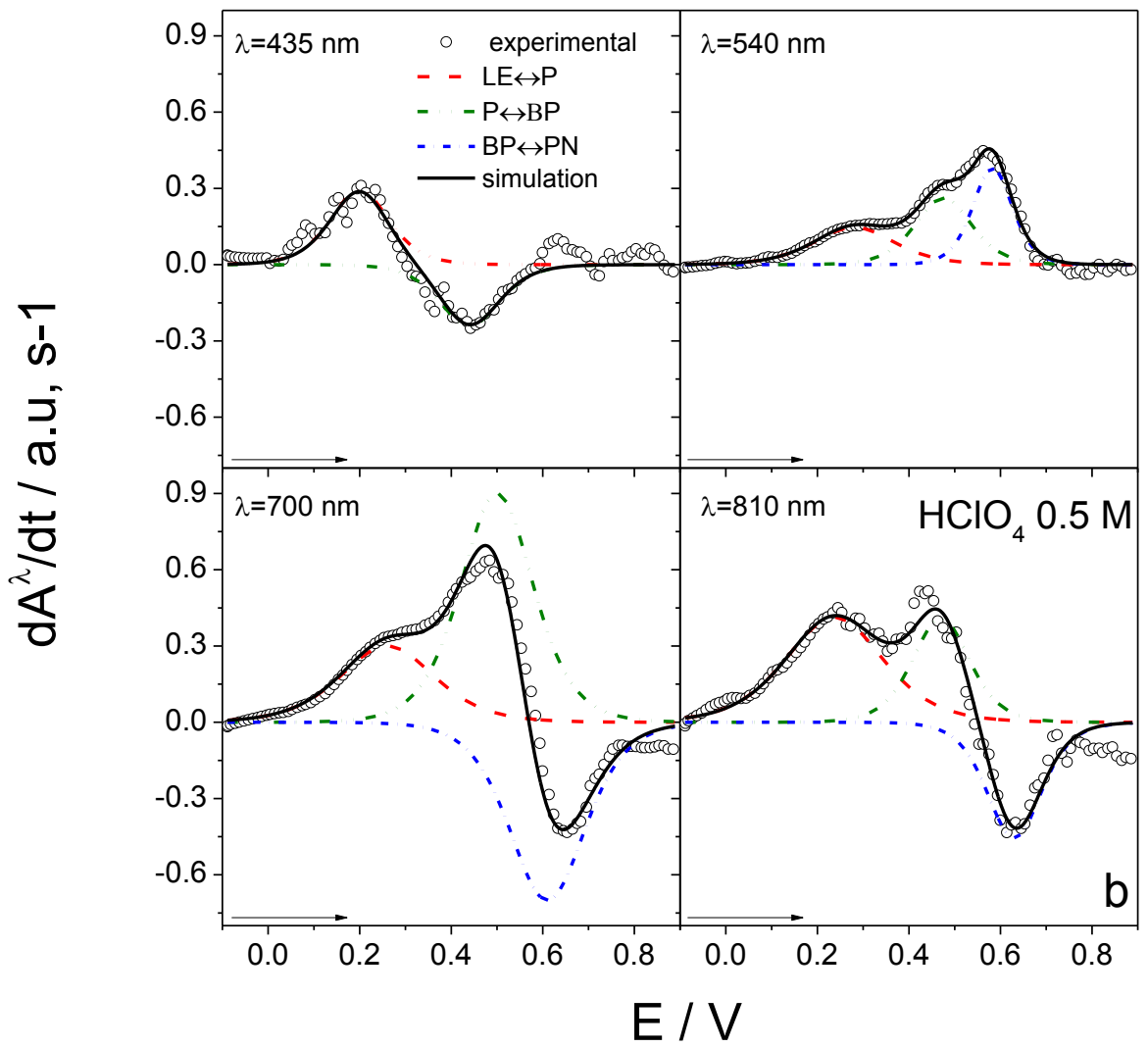

Figure $2 b$ 


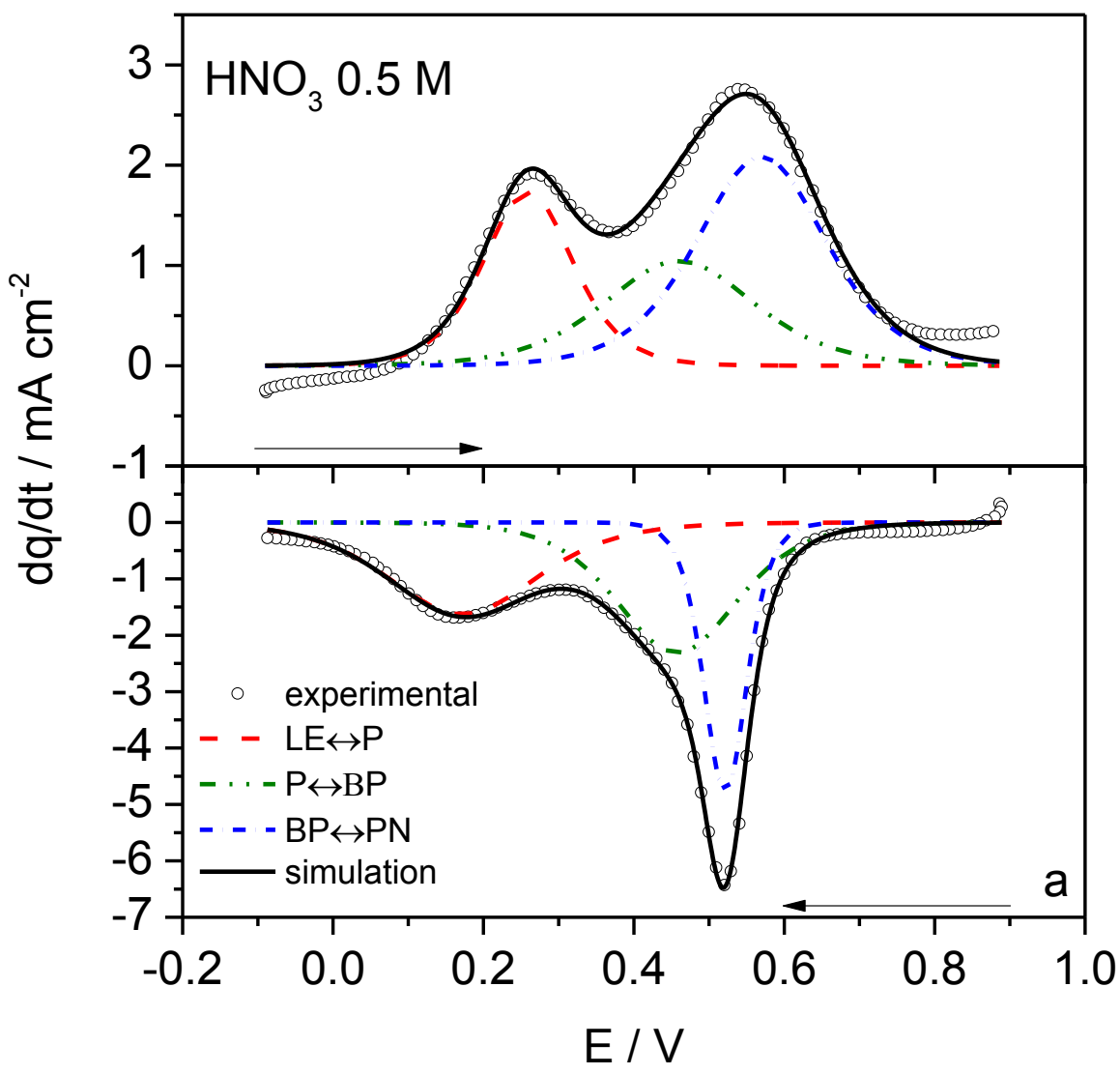

Figure $3 a$ 


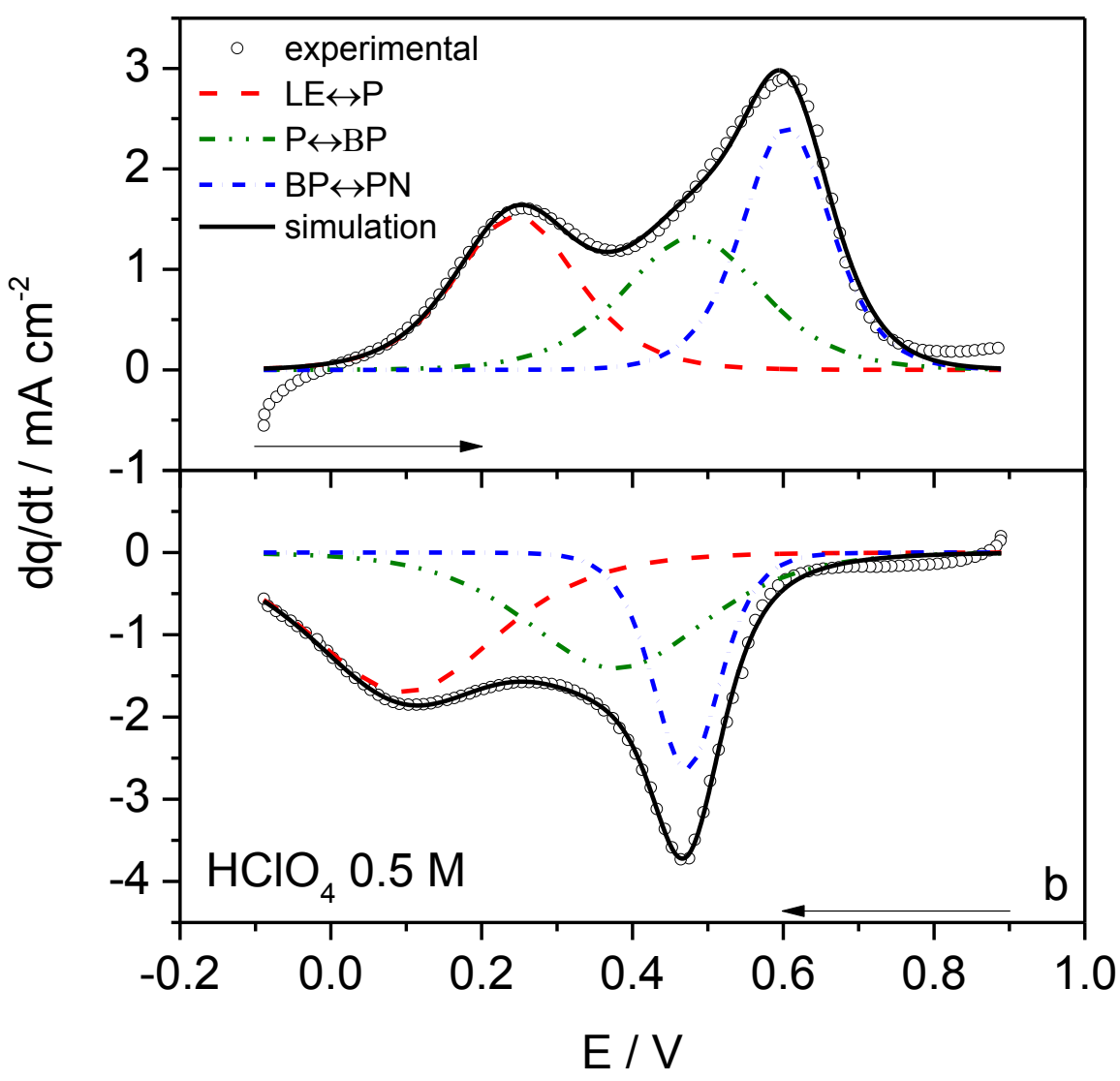

Figure $3 b$ 


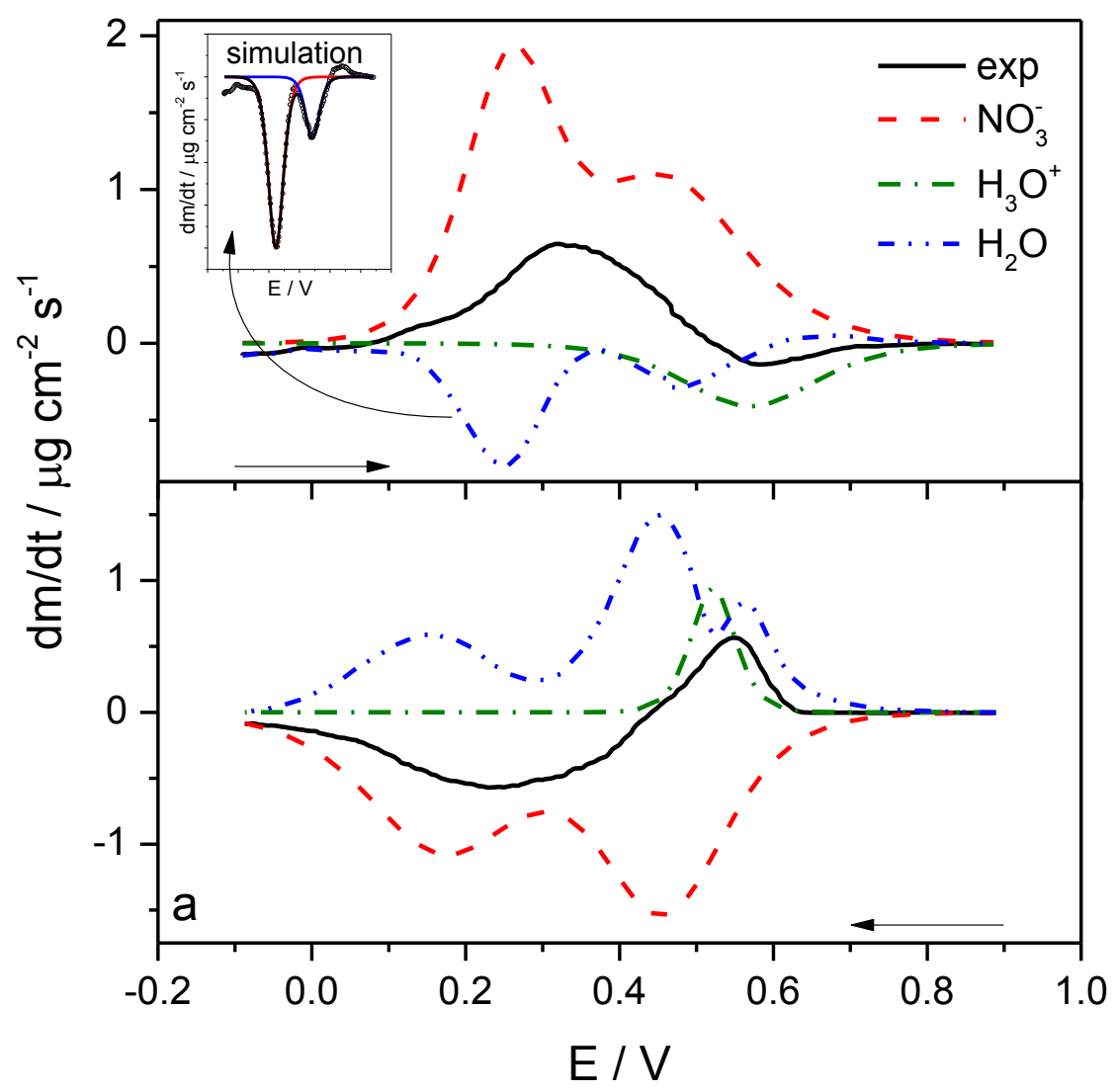

Figure 4a 


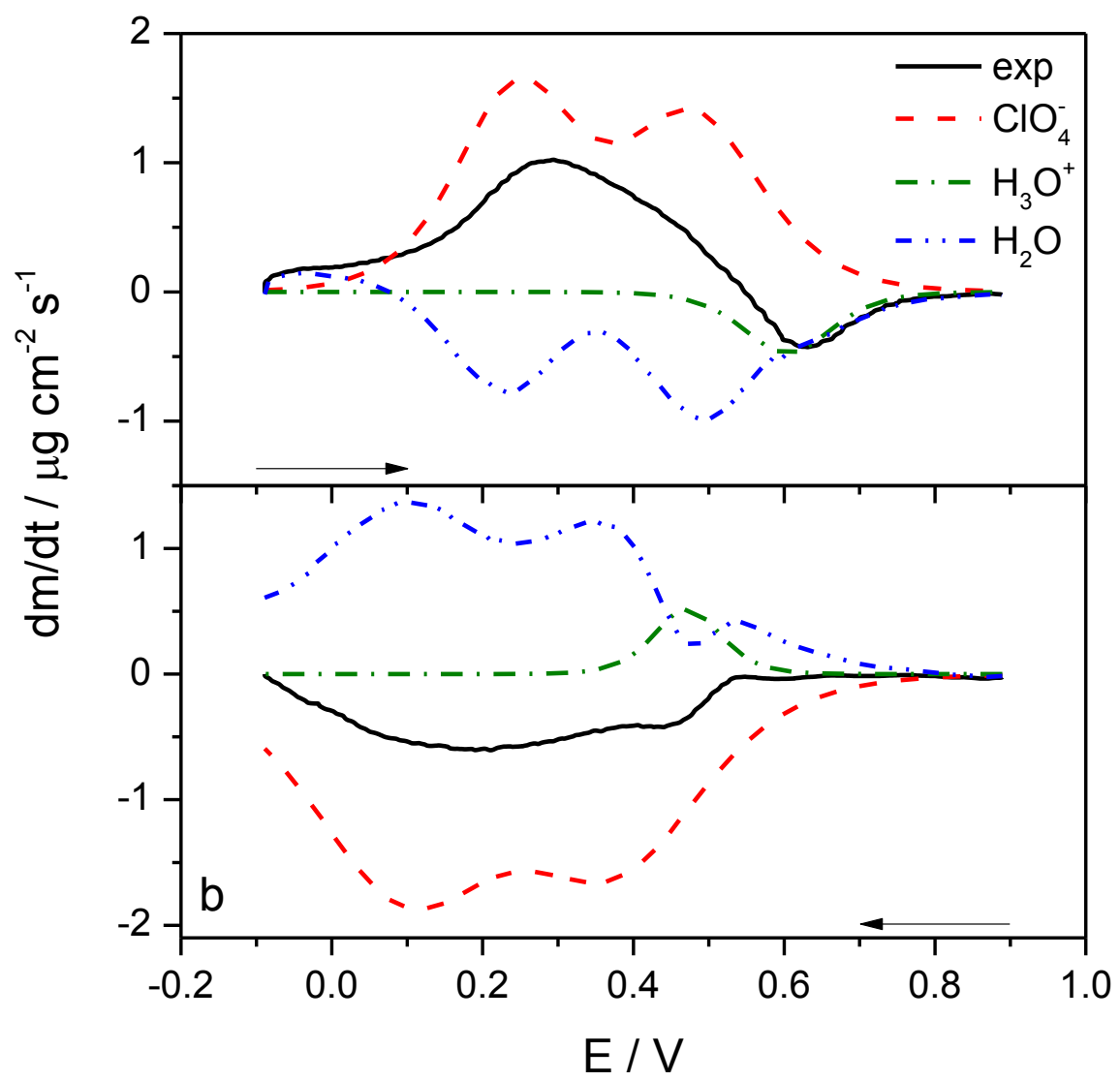

Figure $4 b$ 


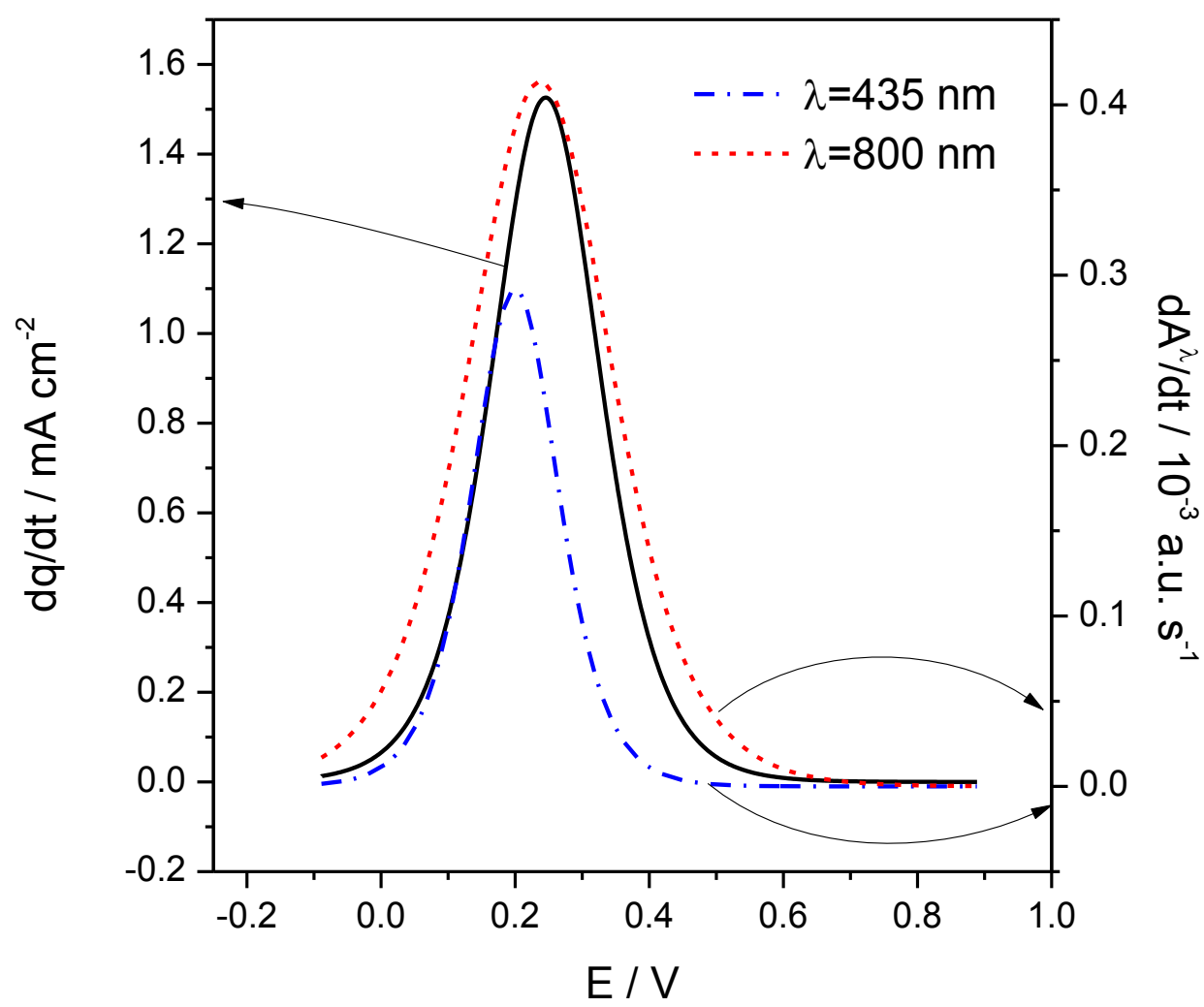

Figure 5 


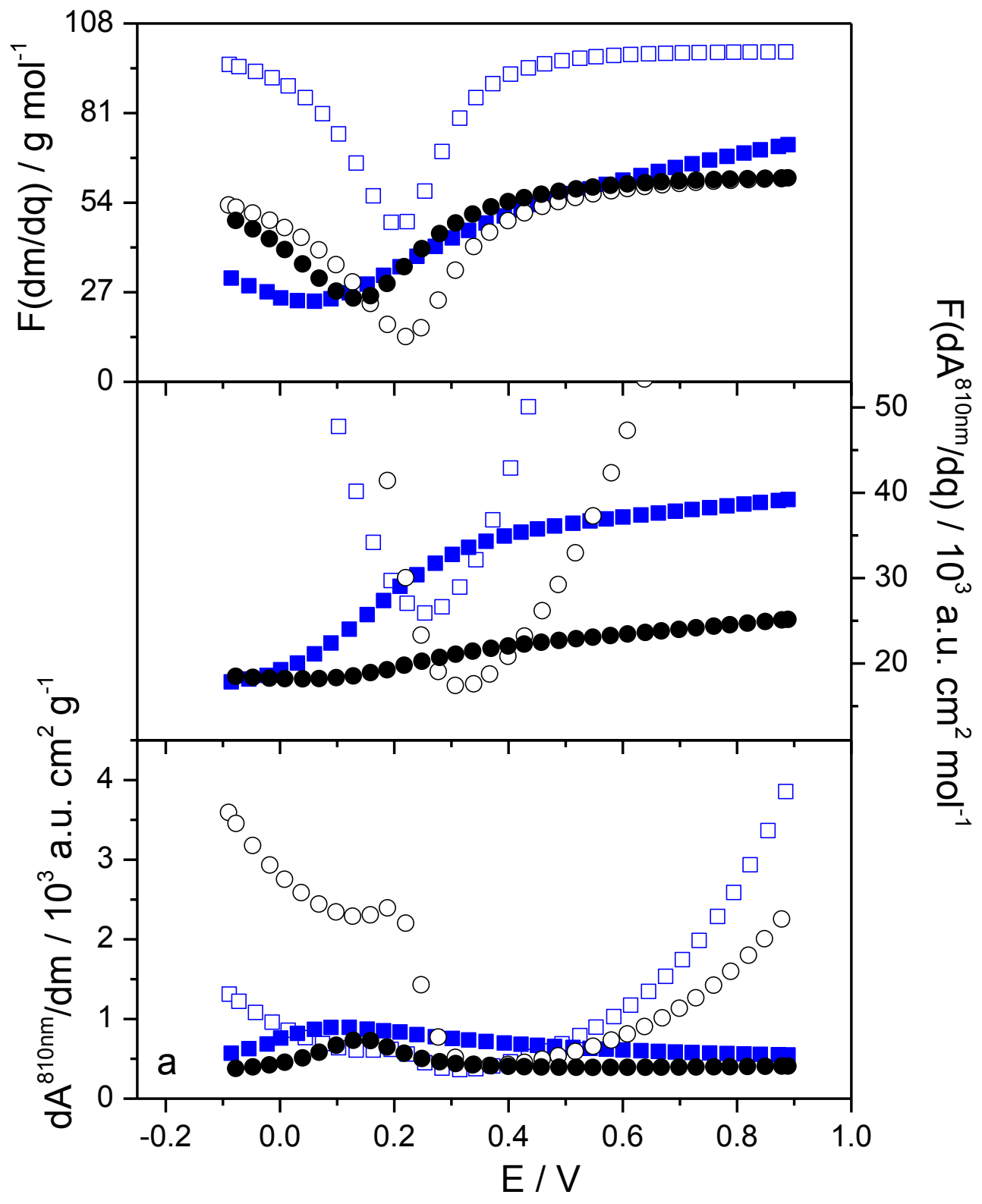

Figure 6a 


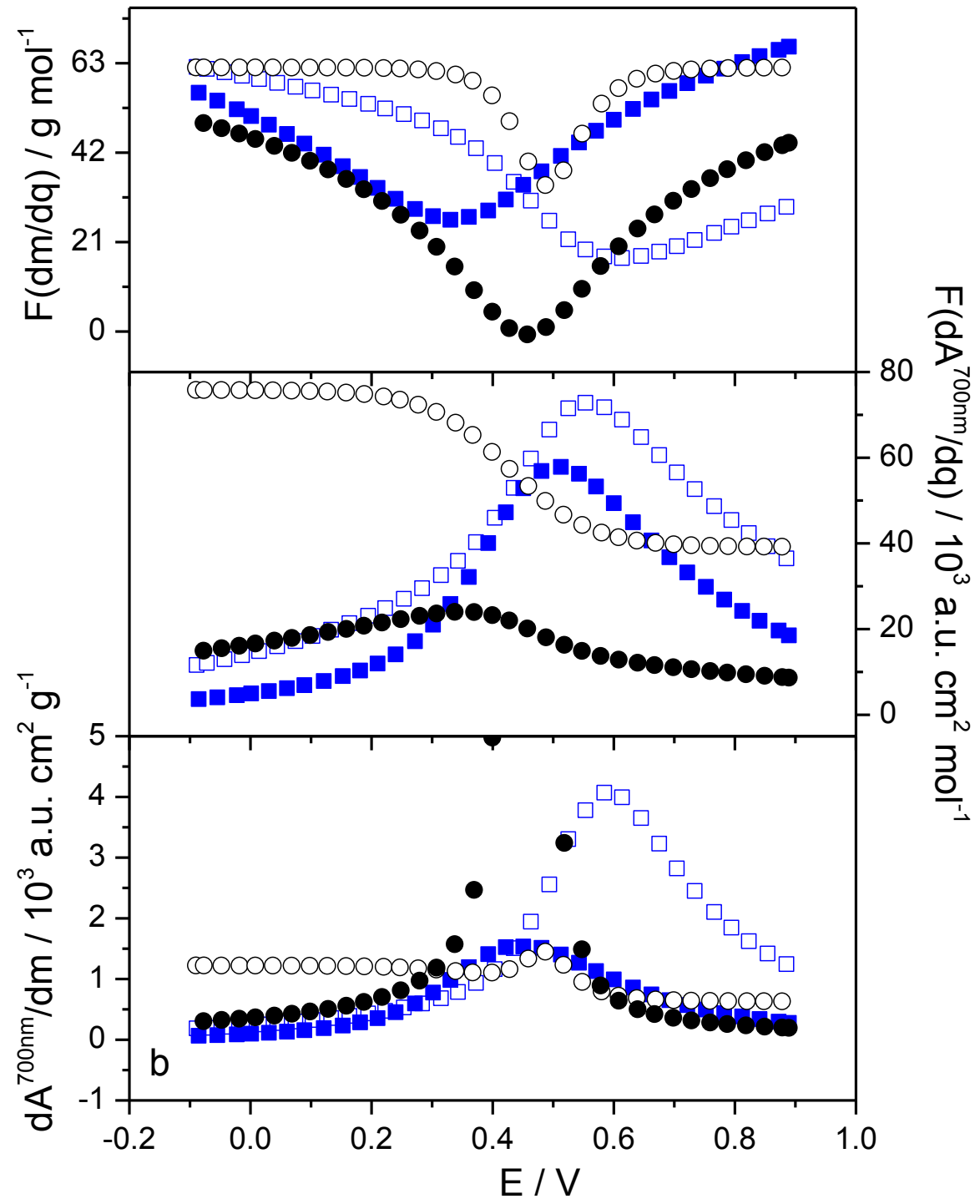

Figure $6 b$ 


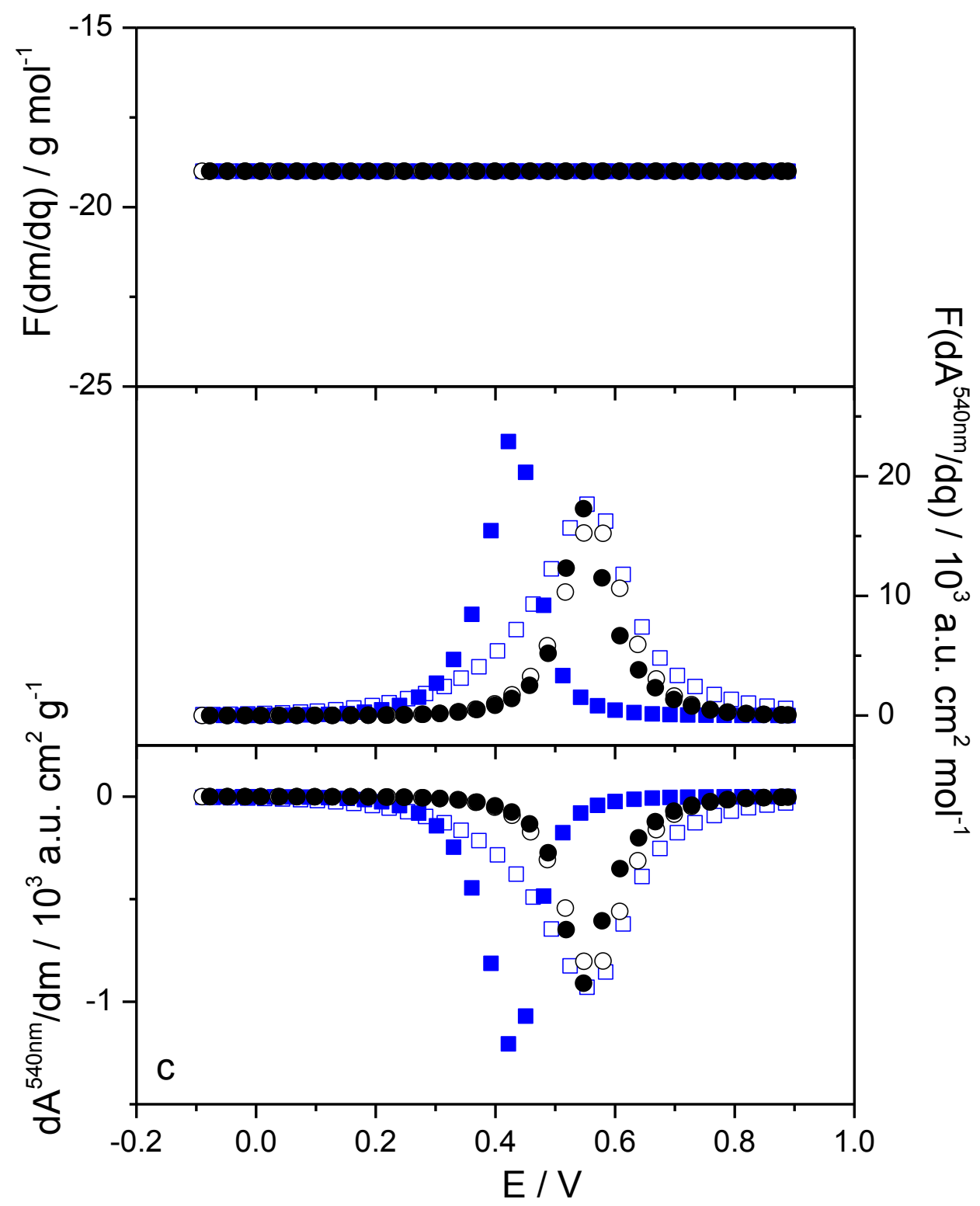

Figure 6c 